\title{
A new 3D geological modeling method based on remote sensing and its application in Ya'an Area sichuan Province
}

\section{zhaoyang Ma ( $D$ 1066061564@qq.com )}

Physical Geological Data Center of Natural Resources

lihai zhang

Physical Geological Data Center of Natural Resources

yan wang

China Three Gorges University

guifan zhu

Physical Geological Data Center of Natural Resources

yinping liang

Physical Geological Data Center of Natural Resources

\section{Research Article}

Keywords: Multi-source heterogeneity, remote sensing, large-scale high-precision modeling, grid division, geostatistics, spatial interpolation

Posted Date: September 7th, 2021

DOl: https://doi.org/10.21203/rs.3.rs-857848/v1

License: (1) This work is licensed under a Creative Commons Attribution 4.0 International License. Read Full License 


\title{
A new 3D geological modeling method based on remote sensing and its application in Ya'an Area sichuan Province
}

\author{
Zhaoyang Ma ${ }^{1}$, Lihai Zhang ${ }^{1}$, Yanwang ${ }^{2}$, Guifan Zhu', Yinping Liang ${ }^{1}$ \\ 1.Physical Geological Data Center of Natural Resources, Sanhe 065201, China; mzhaoyang@mail.cgs.gov.cn \\ (Z.M.); zlihai@mail.cgs.gov.cn (L.Z.);zguifan@mail.cgs.gov.cn(G.Z);lyinping@mail.cgs.gov.cn (Y.L.); \\ 2. China Three Gorges University, Yichang 443000, China; wangyanteacher@yeah.net(Y.W.) ;
}

\begin{abstract}
Remote sensing technology provides a new way to explore the earth for geoscience applications. In the context of continuous deepening of geological research and the vigorous development of geospatial information science, 3D geological modeling technology has become a research hotspot in the intersection of earth science and information science. In this study, remote sensing technology is adopted to improve the traditional 3D geological modeling method, so that geological modeling can be integrated with remote sensing image, and a new 3D geological modeling method based on remote sensing technology is developed. This method can perform integrated 3D visualization of underground and aboveground scenes. The new 3D geological modeling method is mainly applied in the geological field, and has made new progress in multisource heterogeneous geological data fusion, large-scale high-precision modeling, geological grid subdivision, attribute modeling technology, remote sensing image fusion and other aspects. Taking the Ya'an area as an example, this paper makes use of the new generation of 3D geological modeling technology to carry out 3D geological modeling and visual display. The 3D visualization in Ya'an area verifies the feasibility and effectiveness of the new 3D geological modeling method based on remote sensing technology in the current data environment.
\end{abstract}

Keywords: Multi-source heterogeneity, remote sensing, large-scale high-precision modeling, grid division, geostatistics, spatial interpolation,

\section{Key technologies of the new 3D modeling method}

\subsection{Overview}

The new 3D geological modeling method refers to the new systematic method developed using traditional 3D geological modeling technology after integrating new computer technology, remote sensing technology, and geostatistics method. Based on the concept of this method, we have developed a software for in-depth exploration in geosciences.

\subsection{Multi-source heterogeneous data processing technology}

\subsubsection{Characteristics of geological data}

Three-dimensional modeling data are characterized by multi-source heterogeneity, that is, by using multiple data, such as remote sensing, borehole, profile, and geophysical exploration data, to describe the geological 
phenomena in the same area. Each type of data may have multiple sources, that is, multiple units. Although the geological phenomena in a given area are specific, it is difficult to ensure the consistency and correctness of these multi-source heterogeneous geological data, which leads to uncertainty about the quality of geological big data. Therefore, it is necessary to process the data to establish an accurate 3D geological model.

\subsubsection{Isomerization of heterogeneous data}

Multi-source remote sensing information/data fusion is an integrated processing and analysis technology for remote sensing information, particularly promising for the synthesis of remote sensing data and multi-source information for geoscience research [1]. Multi-source heterogeneous data processing technology is the basis of geological modeling using data from multiple sources. Regardless of the source of the data, be them geophysical exploration data, borehole data, plane geological map, section map, or topography and remote sensing data, the main issue in the use of this technology lies in the conversion of heterogeneous data into isomorphic vector data (points and lines) and the provision of basic data sources for the generation of surfaces, such as ground level, fault level, and rock mass surface. The isomer pretreatment results of heterogeneous data are shown in Table 1.

\begin{tabular}{|c|c|c|c|}
\hline Data type & Geologic body & Data sources & Pre-treatment result \\
\hline \multirow{4}{*}{ Point } & Stratigraphy & $\begin{array}{c}\text { Drill、DEM、TIN Gridding、Geophysical interpretation } \\
\text { of discrete points }\end{array}$ & \begin{tabular}{|c} 
Drill Stratigraphic layering point \\
collection
\end{tabular} \\
\hline & Fault & Drill、TIN Gridding & Borehole breakpoint set \\
\hline & Intrusions & Drill、 TIN Gridding & Rock mass interface point set \\
\hline & Property & Remote sensing image, Monitoring point, Point cloud & Status Point \\
\hline \multirow{10}{*}{ Line } & \multirow{3}{*}{ Stratum } & Profile line & Formation line assembly \\
\hline & & Planar geological map stratigraphic boundaries & Formation line assembly \\
\hline & & Line of geophysical interpretation & Formation line assembly \\
\hline & \multirow{3}{*}{ Fault } & Sectional view of the fault line & Fault line assembly \\
\hline & & Fault lines in surface geological maps & Fault line assembly \\
\hline & & Geophysical interpretation of broken edges & Fault line assembly \\
\hline & \multirow{3}{*}{ Intrusions } & A profile of the boundary line of the invasion & Set of invasion boundary lines \\
\hline & & Surface geological map invasion boundaries & Set of invasion boundary lines \\
\hline & & Geophysical exploration explains the boundary & Set of invasion boundary lines \\
\hline & Property & $\begin{array}{l}\text { Contour lines, geological map regional boundaries, } \\
\text { Sedimentary facies regions, Logging curves }\end{array}$ & Set of invasion boundary lines \\
\hline
\end{tabular}

Table 1 Results of isomerization pretreatment of multi-source heterogeneous data

\subsubsection{Data conflict priority}

Another core problem that can be solved using multi-source heterogeneous data processing technology is the priority level of conflicting data in the modeling process when various types of data are in conflict. This technique adopts the principle of precision in data processing, that is, the priority of use of source data is positively correlated with the exploration accuracy of source data. The higher the accuracy, the higher the priority.

\subsection{Large-scale integrated high-precision modeling}

\subsubsection{Working principle}


Large-scale high-precision holistic modeling allows for the establishment of a continuous 3D geological model that meets the precision requirements for a wide range of geological research areas and covers the entire research area. This technique mainly uses model database and data extension technology. With the support of model database technology, the overall modeling of different strata in a large area is conducted, and the precision of the local model reaches that of the conventional block model. By using data extension technology, boundary faults and strata can be spliced and fused together in order to improve the understanding accuracy of boundary faults. On the other hand, large-scale high-precision overall modeling is based on the processing of complex structures, ensuring consistency of model information, achieving high-precision fusion of multiple work areas, and solving the problem of effective inheritance of existing modeling achievements. At the same time, largescale high-precision overall modeling enables the unified storage of data and models, and the construction of a unified management and communication platform. This technique targets relatively deep and mature geological research or mineral production areas for exploration and development, which are characterized by wideness, multiple types of geological data, and large amount of data in general. The overall model constructed can accurately describe all geological structures in a given area. Conversely, the holistic model is the basic model for fine geological management. Finally, large-scale high-precision global modeling can provide precise geological description, fast data calculation, and real-time dynamic updating. The working principle of largescale high-precision overall modeling is shown below (Figure 1).

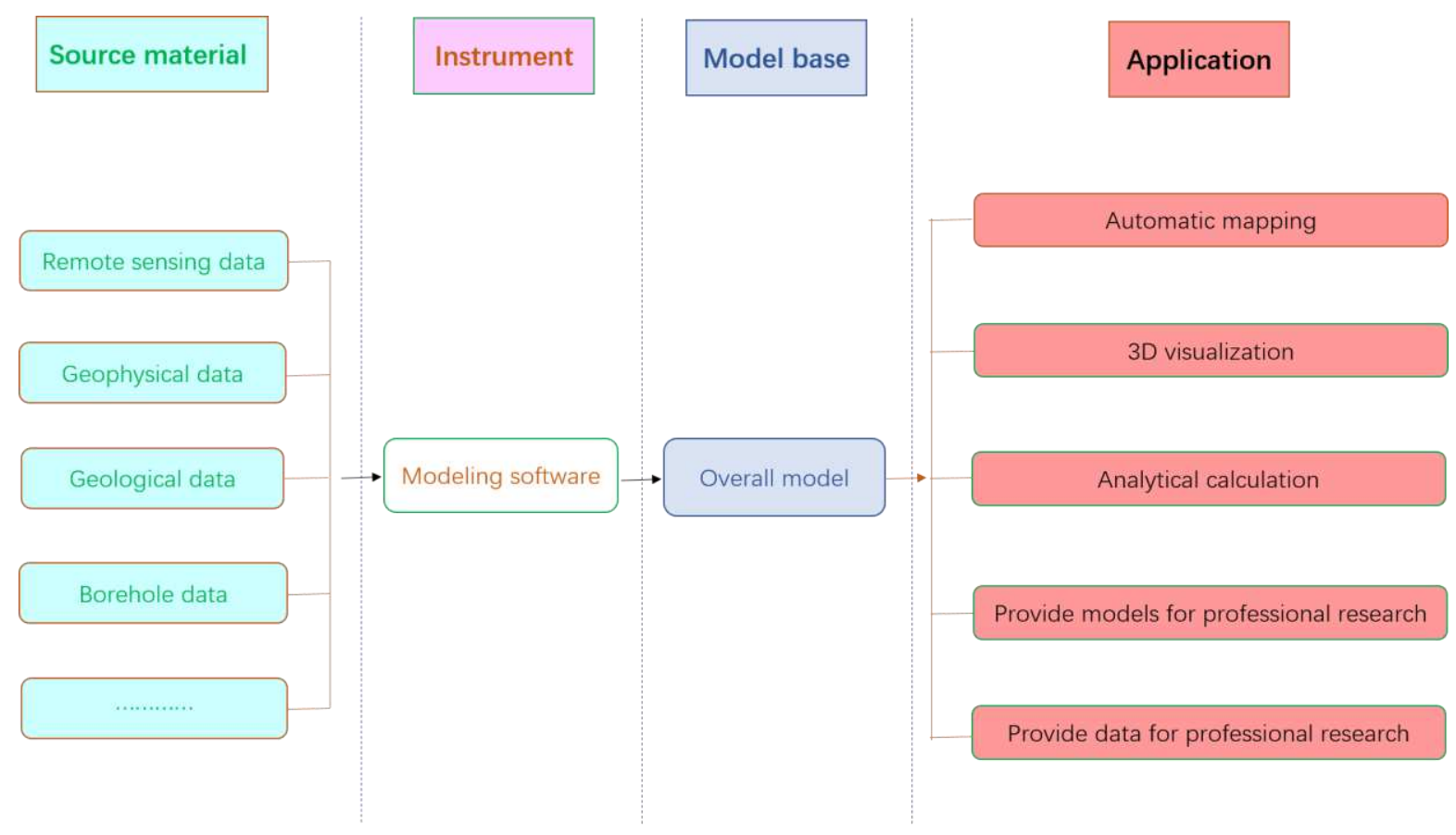

Figure 1. Working principle of large-scale overall modeling

Given Figure 1 above, the overall modeling working principle is as follows. The raw data are first stored in a database. Then the model database technology, the local modeling seamless mosaic technology, and the multiperson parallel working mode are used to build the whole model. Finally, cluster visualization technology is used to depict the overall model and carry out various applications based on the model. 


\subsubsection{Overall model database technology}

The whole model database technology breaks the traditional model file storage mode. It adopts the chip storage mode and stores the resulting model in the form of field storage, which is the technical core of the model database. The overall model is specified by the user, the cells are partitioned, and the results of the partitioning are saved to a database file. Each cell is stored in a table corresponding to the database, and the table records information as fields. When the local model is downloaded, the locked cell is determined. Local models are exported after being processed into multiple slice models (cell models). What is recorded into the database is the information of each piece of metamodel, which is stored in the form of fields in the corresponding cell table. The procedure to be invoked is similar to the storage. The locked cell model is first extracted from the database and then processed to form a complete model. Finally, the model is loaded into the modeling software to demonstrate the model. The overall model database technology is shown in Figure 2.

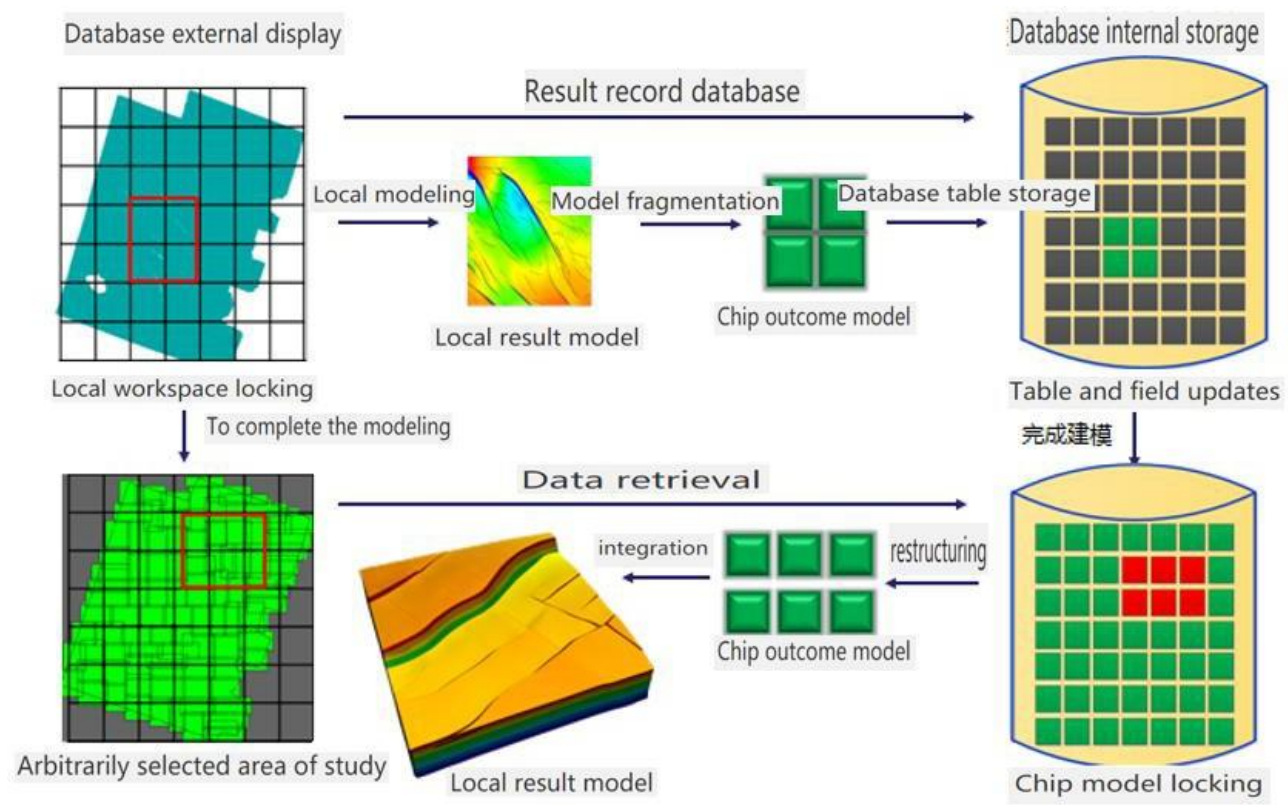

Figure 2. Overall model database technology

\subsubsection{Local modeling seamless mosaics technique}

For the spliced block and small work area, the traditional modeling method can be applied basically. However, if the spliced blocks are too many and too large, the scope of the work area involved will be excessively large to be borne by the computer and software, and then the traditional modeling method cannot be applied. Given this situation, we adopt model database technology to ensure seamless stitching of local models through local splicing and extension grid in order to splice both multiple and large work areas. The principle of seamless mosaics in local modeling of the model database is that all overlapping data are loaded into the database for the unification of the construction. The model of local overlapping area is renewed, and the model and the surrounding model can be seamlessly spliced after the extension grid is updated, achieving the seamless splicing and fusion of multiple work areas. 
There are two essential types of splicing problems. The first comprises the fusion of the early modeling results through the database. The fusion results are shown in Figure 3.

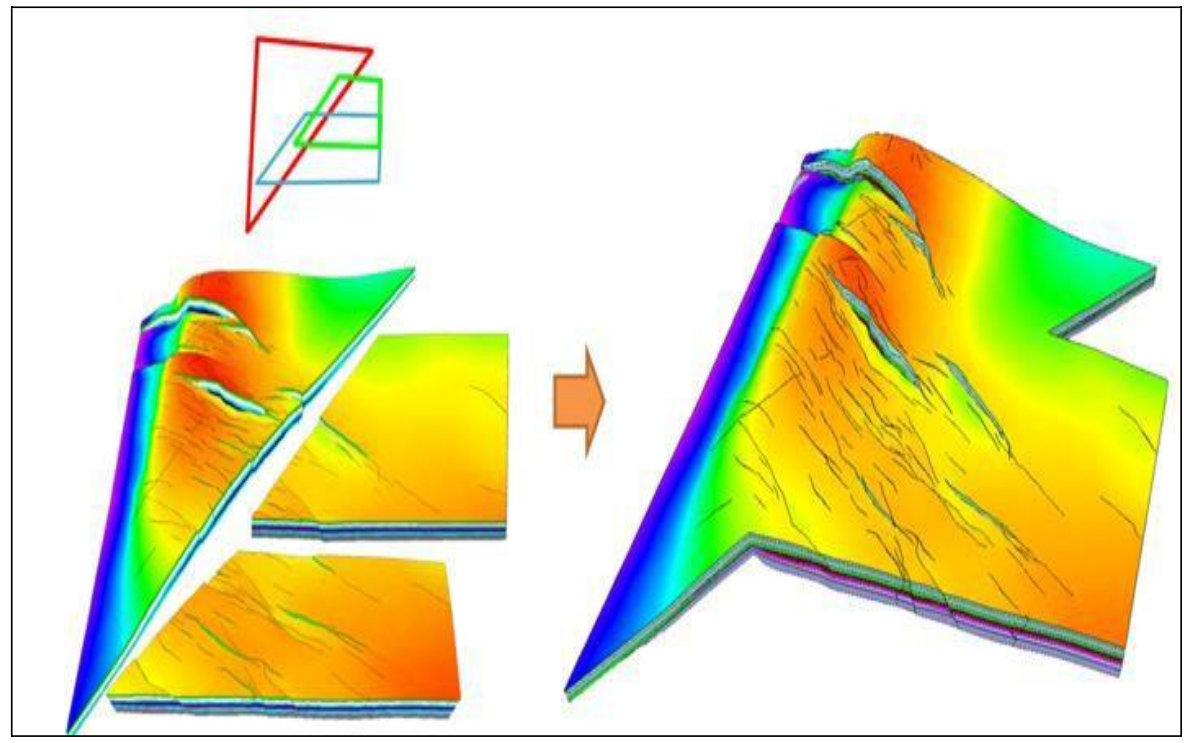

Figure 3. Seamless integration of early model results

In the second, the local model established by multiple people is constructed, and the seamless fusion is conducted automatically in the database, as shown in Figure 4.

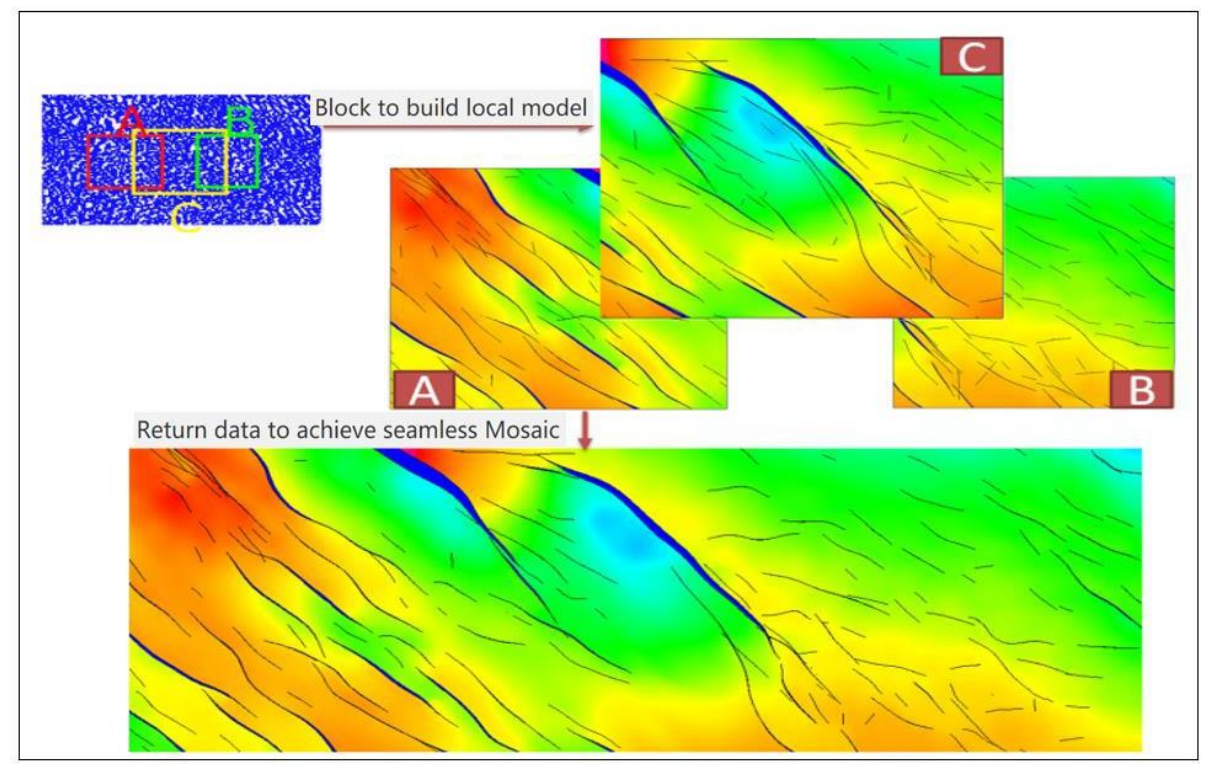

Figure 4. Display of the seamless database fusion effect

In the process of local model modeling, attention should be paid to the modeling method at the splicing point. There are three main ways to address the faults at the splicing of adjacent local work areas. First, seamless splicing can be conducted automatically if the fault involved in splicing is not changed. Second, the splicing point involves fault modification but has no impact on adjacent blocks and automatically conducts seamless splicing. Third, splicing involves fault modification; if the adjacent block is affected, another block should be 
downloaded at the fault layer to re-model to achieve seamless splicing. For the establishment of the stratigraphic model in the splicing area, only the fault model and the stratigraphic data in the splicing area should be consistent. Through this method, the recognition results of boundary faults in adjacent blocks are unified, the modeling results are effectively integrated and inherited, and repetitive modeling is avoided, thus improving work efficiency. The schematic diagram of overlapping area selection is shown in Figure 5.

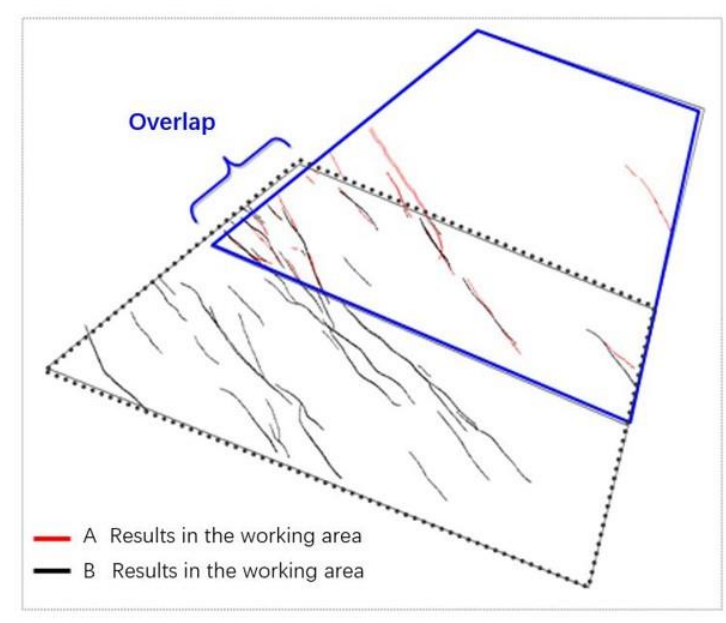

The recognition of boundary faults in different work areas is inconsistent

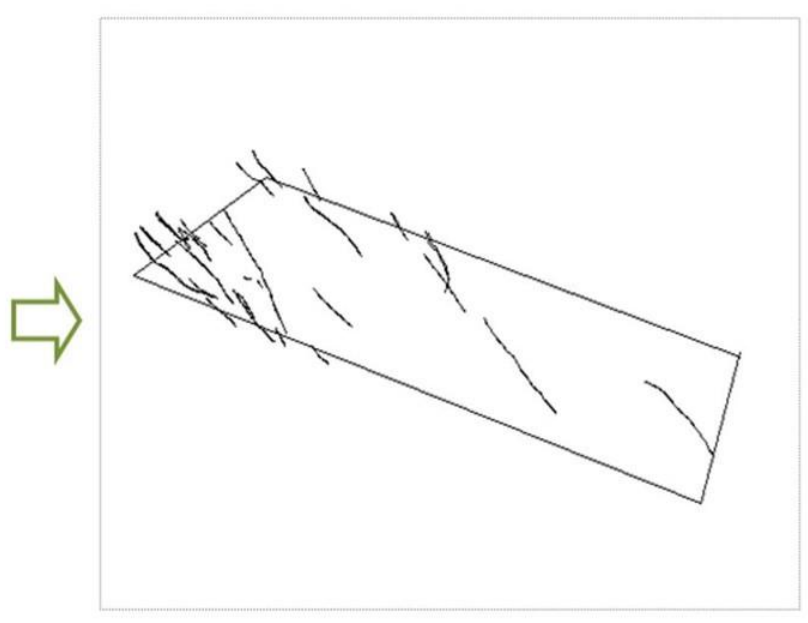

The final result of boundary fault recognition

Figure 5. Schematic diagram of overlapping area selection

\subsubsection{Multi-person parallel working pattern}

Based on the principle of holistic model database, multi-person parallel holistic modeling is implemented by breaking parts into pieces, as shown in Figure 6. It solves the technical problem of regional integral modeling, which is difficult to be realized by conventional one-person small work area modeling.

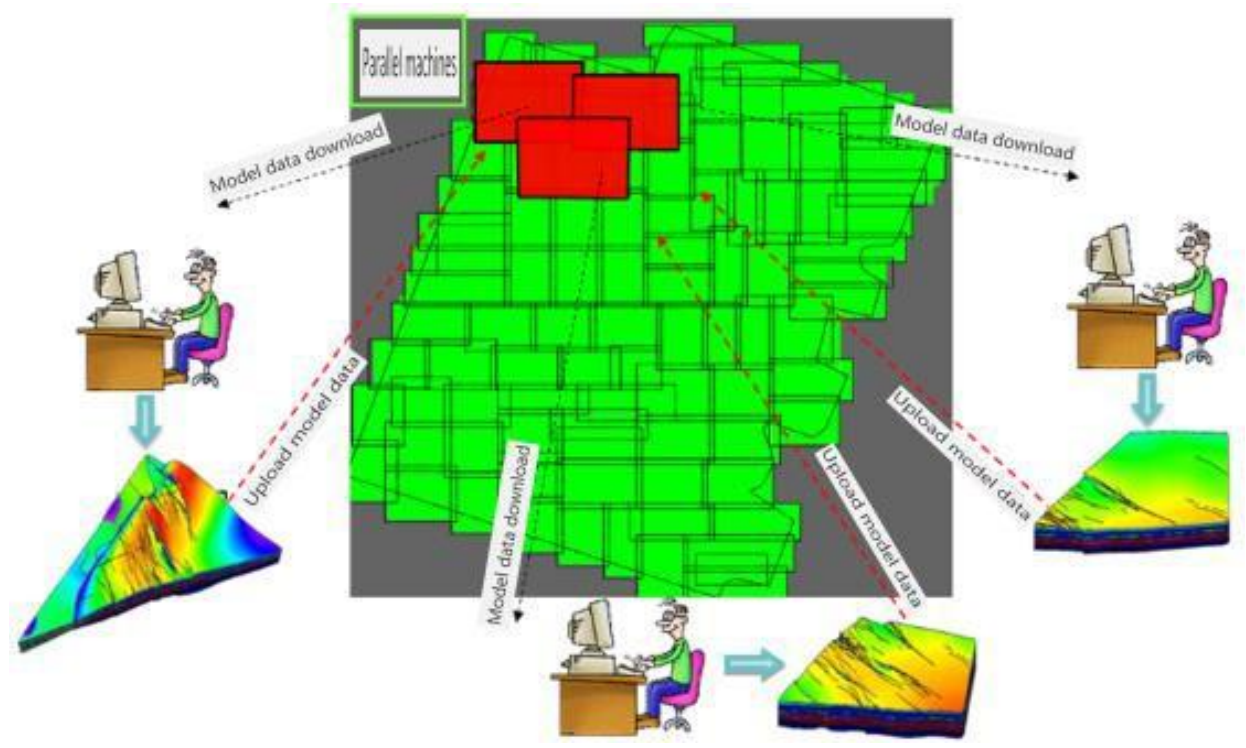

Figure 6. The multi-person parallel working pattern 


\subsubsection{Cluster visualization}

A cluster visualization system is a cluster graphics processing system. This processing system can depict the large-scale overall model and the local model of any size and position, as well as obtain the plan and section of any position, as shown in Figure 7.

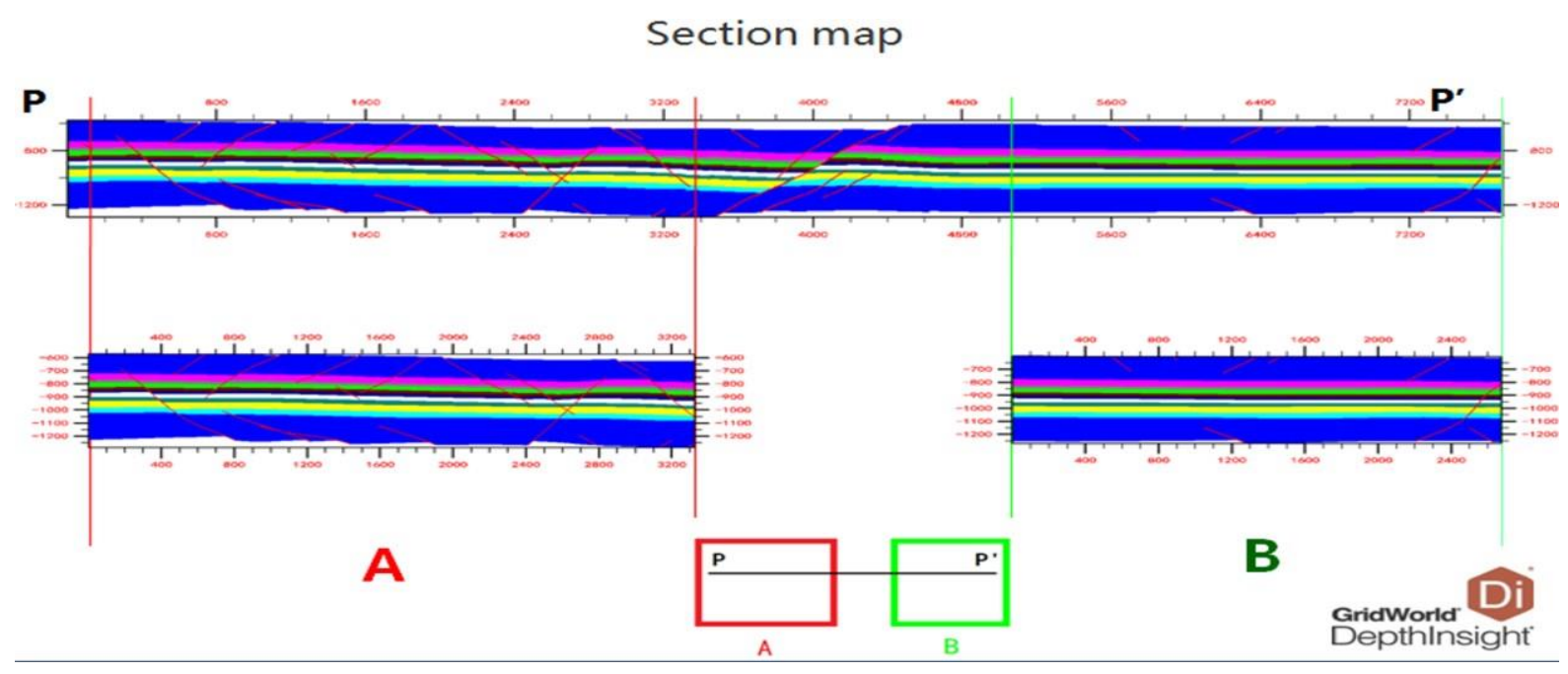

Figure 7. Overall profile of a large-scale high-precision model

\subsection{Grid subdivision technique}

\subsubsection{Technical difficulties}

The grid subdivision technique is the foundation of attribute modeling, quantitative analysis, and numerical simulation. It is also the focus of the new generation of 3D geological modeling technology. The type of grid and the quality of the grid subdivision technology have particular influence on the success of 3D geological modeling. There are two difficulties in 3D mesh generation. First, while the 3D meshing of geological bodies cannot simplify geological conditions, it is difficult to simplify geological information when using man-made structures to cut 3D geological grids. Most 3D geological modeling software has the function of grid subdivision, but different grid subdivision algorithms are used. Second, the 3D mesh models obtained by different mesh generation algorithms significantly influence the accuracy of subsequent analysis and calculation. For traditional grid generation technology, it is considerably difficult to generate 3D mesh that can accurately describe the geological structure and support various analysis and calculation. The new 3D geological modeling method adopts truncated rectangular grid, PEBI grid, corner grid, and integrated grid subdivision technology.

\subsubsection{Truncated rectangular mesh}

The truncated rectangular grid is an irregular grid. Its obvious advantage is that the mesh at the fault layer is expressed by polygons, so that the fault structure can be guaranteed without loss of structural information. In addition, compared to the tetrahedral mesh, the truncated rectangular mesh is simpler and more efficient in spatial data organization, in addition to support subdivision under complex structural constraints. The truncated rectangular grid is shown in Figure 8. 


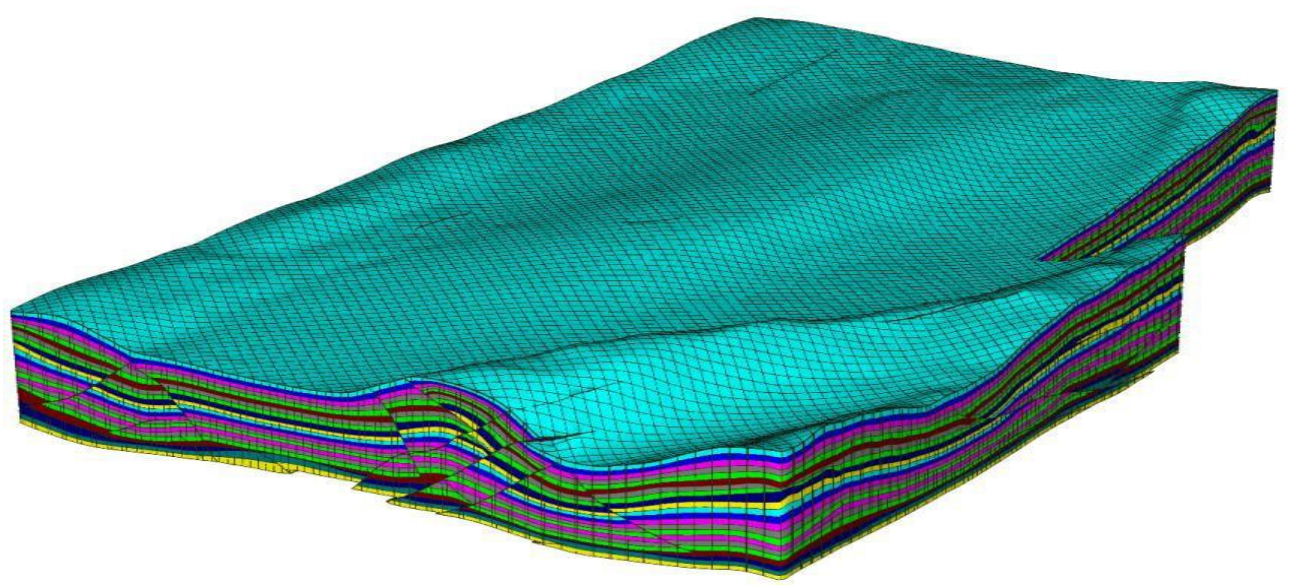

Figure 8. Diagram of the truncated rectangular grid

\subsubsection{PEBI grid}

PEBI grids are unstructured grids. They can ensure smoothness without serrations in the strata and faults. The data is encrypted around the borehole to make the simulation more accurate. PEBI grids also support subdivision under complex construction constraints. A PEBI grid is shown in Figure 9.

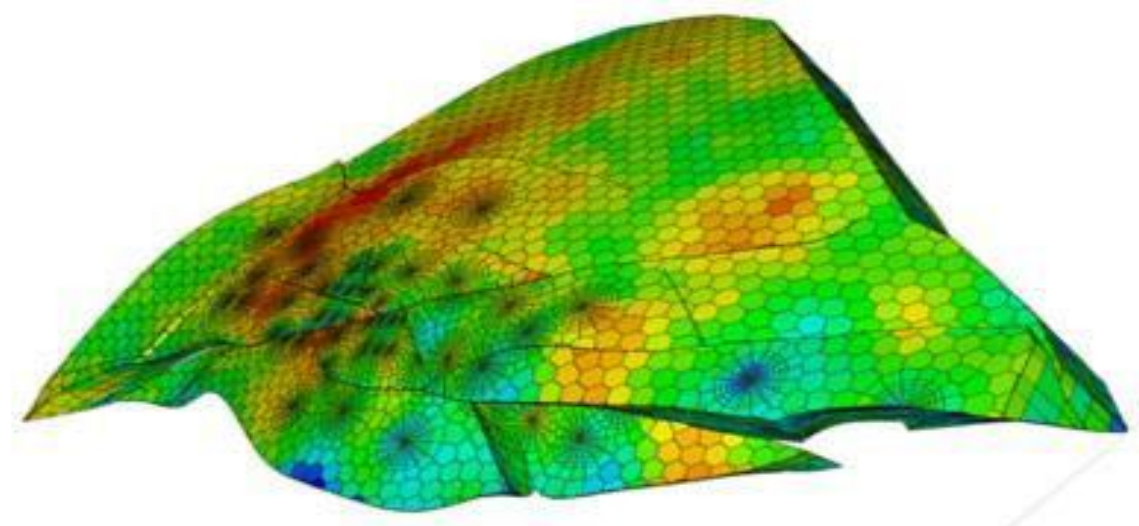

Figure 9. Schematic PEBI grid

\subsubsection{Corner-point grid}

A corner-point grid is a common grid format used in reservoir geological modeling and numerical simulation. After the structure information is obtained, a corner-point grid also supports subdivisions under complex structure constraints. However, some structural information will be lost at ground annihilation and fault intersection. In addition, the corner mesh model generally does not support local updating of the model.

\subsubsection{Raster}

Raster is a simple regular grid with simple spatial position expression. Its ability to describe complex geological bodies is limited, as well as its ability to express structure information, which is usually expressed by attribute interface. 


\subsection{Key techniques of attribute modeling}

\subsubsection{Attribute interpolation}

Attribute modeling is a geological model based on structural model and calculated using the geostatistics method. It includes discrete (sedimentary and lithofacies) or continuous (such as water content, weight, permeability, and saturation) properties. Common interpolation algorithms are the kriging method, the sequential simulation method, and the inverse distance weighting method. Kriging interpolation is a statistical grid method. In this new 3D geological modeling method, two kriging methods, namely ordinary kriging and directed kriging, are used to interpolate different types of attributes. In ordinary kriging interpolation, the attribute value of the unknown point is considered to be the weighted sum of the attribute value of the known point. It is a simplified version of the kriging method used for continuity determination interpolation. The indicator kriging method is adopted to transform the investigation of the regionalized variable $\mathrm{Z}(\mathrm{u})$ into the investigation of its indicator function. It does not depend entirely on the stationarity of the regionalized variable, nor does it require them to obey a certain distribution. The method allows the estimation of the value of each part falling on some interval and the value of the part that is higher or lower than a certain threshold value. Different threshold values are used to divide the original data into appropriate intervals, and information from various sources is indicated and coded. This method can be used to determine the interpolation of discrete attributes.

The basic function of sequential simulation is to obtain the local conditional probability distribution (LCPD) of each grid point sequentially along a given random path, and then extract the simulation value randomly from the LCPD. The simulation process is carried out sequentially from one pixel to another and is used to calculate the data of a pixel's conditional probability distribution function. In addition to the conditional data except the original data, all data that have been simulated are considered. This new 3D modeling method uses sequential indication and sequential Gaussian methods, which are simulation methods suitable for different types of attribute interpolation. The sequential indicator simulation method (SISM) is used mainly to infer the variogram of the reservoir spatial attribute parameters, establish a random model based on the variogram, and then perform random simulation to provide the spatial distribution results of attribute parameters. This method is used for random interpolation of discrete attributes. Sequential Gaussian simulation, in turn, directly produces a Gaussian field model implementation. It is based on the concept of sequential simulation and is suitable for random interpolation of continuous attributes.

Inverse distance weighting refers to the inverse distance squared method. It is a weighted average interpolation that can be precisely or smoothly interpolated. The quadratic parameter controls how the weight coefficient decreases as the distance from a grid node increases. For a larger square, the closer data points are given a higher weight share. For a smaller square, the weight is more evenly distributed among the data points. [2] This method is used to determine the interpolation of continuous attributes.

\subsubsection{Data analysis}

Data analysis is a method of data research, data control, identification of key geological features, and data preprocessing prior to modeling. The modeled attribute data can be divided into discrete and continuous, which 
correspond to different data analysis methods. Variational function is a method used to describe the variation of the reservoir property that is based on the principle that the correlations between small samples are greater than those between relatively distant ones. When the distance exceeds a certain range, the additional change of distance has little influence on the correlation. Discrete attributes can be analyzed using the variational function directly, whereas continuous attributes need to be transformed first. In this study, we developed trend removal algorithms for input truncation, output truncation, logarithmic transformation, exponential transformation, standardization, 1D, 2D, and 3D. This method adopts the experimental variational function, which needs to be fitted. The fitting function of the experimental variational function is not arbitrary. In this context, previous studies have indicated four theoretical variational function models that can be used for fitting, as shown in Figure 10.

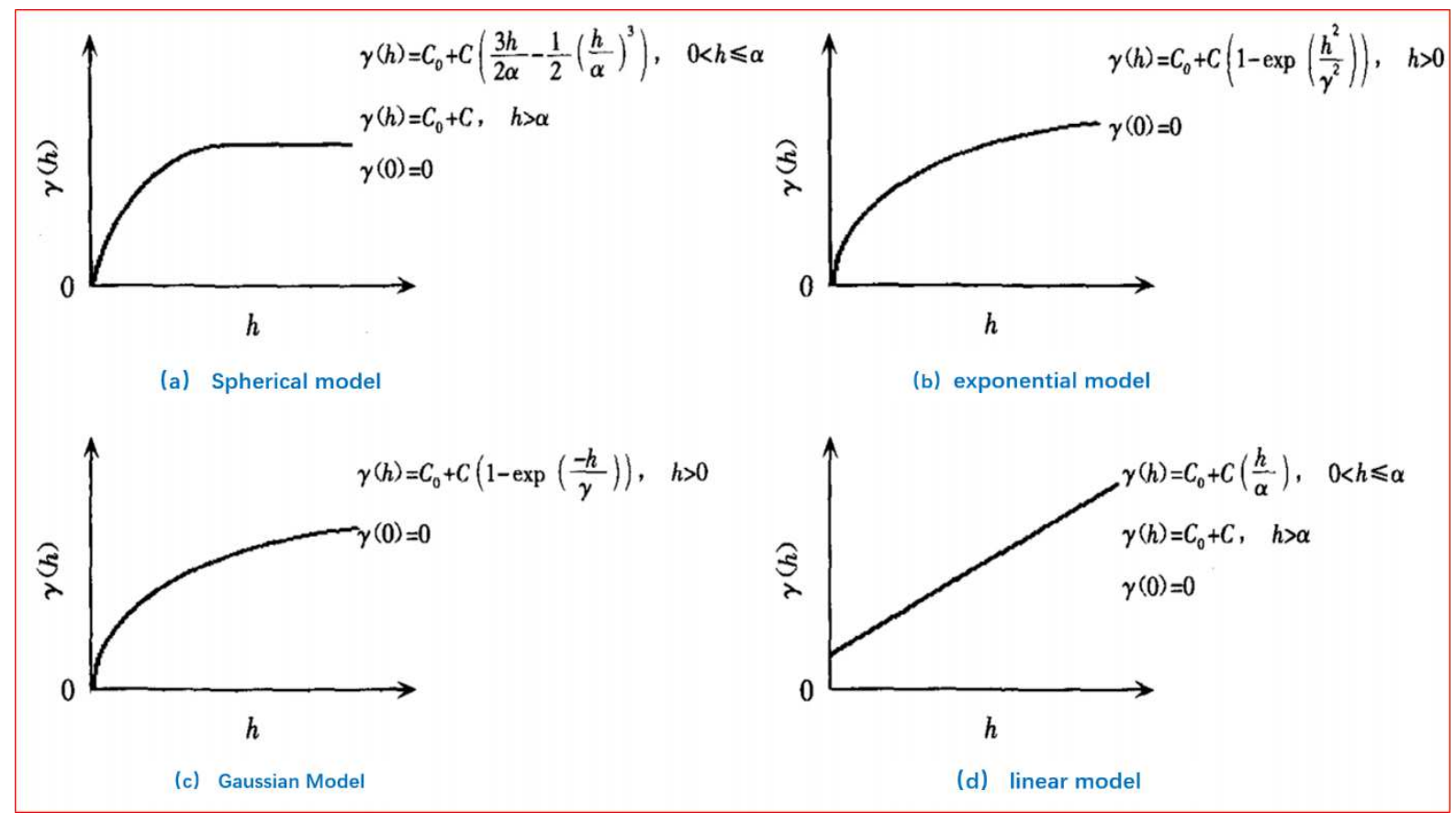

Figure 10. Theoretical variational function model

It should be noted that the spherical model is the most widely used model in geostatistics,as it can be used to fit many variables and the effect is relatively ideal. In addition, the variational function contains three essential parameters, namely sill, range, and nugget. Then nugget value $\mathrm{C} 0$ is the intercept of the function on the $\mathrm{Y}$-axis, indicating the discontinuous change of the variable when it is less than the sampling scale. The base station value $\mathrm{C} 0+\mathrm{C} 1$ is the maximum value of the function and represents the maximum variation in the attribute. The range $\mathrm{a}$ is the minimum lag distance where the value of the function does not change. It indicates that, when the lag distance is greater than a, the spatial correlation of the variable disappears, reflecting the influence range of the variable. The computing capacity has improved with the continuous progress of science and technology, promoting the rapid development of numerical methods, which can combine the non-uniformity of materials and structures [3,4] and the investigation of underground characteristics [5].

\subsection{Application of remote sensing technology}




\subsubsection{Summary}

Remote sensing technology uses different types of sensors located at different distances to obtain information on the earth. Since the first remote sensing image, it has been used for land use, hydrology, geology, weather, climate, and vegetation research [6,7]. Satellites and aircraft equipped with optical, radar, or laser sensors are the most common means of collecting and investigating data on the earth's surface. [8] With the development of these traditional remote sensing technologies, UAV has been widely used in environmental research in recent years. [10-13] However, satellite remote sensing is still used for regular monitoring of large areas. [14,15] The main advantages of satellite imagery are free access to data and different spatial and temporal resolutions. [16] The development of remote sensing has greatly broadened the horizon of field-related technology and is becoming an indispensable technical means for geological research and 3D modeling. The observation scale, resolution, and recognition accuracy of remote sensing have greatly improved with the enhancement of various sensor parameters. At the same time, remote sensing geology has achieve a qualitative leap from macroscopic to microscopic detection and from qualitative interpretation to quantitative inversion, pushing remote sensing geology and application to a new height [17]. Remote sensing image processing, multi-spectral alteration anomaly extraction, hyperspectral mineral identification and mapping, InSAR surface deformation investigation and monitoring, remote sensing ore prospecting model, and remote sensing geological disaster investigation and monitoring are the main research directions. In this context, research outcomes play an important role in the prediction of structural morphology, lithology, and attribute distribution of 3D geological models [18]. One of the main advantages of remote sensing technology is its potential to identify and extract the scope and element information of built-up areas for planning and resource management, risk assessment, and disaster early warning [19-21].

Due to the rock mass fault, the formation of the structure is closely related to the interaction of the rock mass, making it possible to analyze and compare the faulted structure characteristics of adjacent rock masses through their spatial distribution characteristics. For example, ETM+ remote sensing image is used as the information source to extract linear structure information by using remote sensing image of rock mass. The isodensity map, trend surface, and stress field distribution are compared, and then the genetic relationship of rock mass is obtained through comprehensive analysis. [22] Remote sensing image data refers to the image data obtained from various sensors, processed by error, and corrected by radiation. With the rapid development of modern remote sensing technology, remote sensing has become a crucial tool to obtain information from remote sensing images because of its macroscopic reach, dynamism, quickness, accuracy, and comprehensiveness. [23] Over the past few decades, satellite imagery products have been the most commonly used auxiliary data sets for mapping, comprising, for example, land cover, land use data, and noctilucent (NTL) images. [24-27] Currently, the acquisition methods of surface DEM mainly include field survey, map digitization, optical detection and ranging, and interferometric synthetic aperture radar (IN-SAR), among others. $[28,29]$ The rapid development of information technology has led to the availability of many DEM data on the Internet to be downloaded and borrowed. Landsat and Sentinel are examples of satellite projects that provide free data. [30,31]

1.6.2 Remote sensing image processing 
A major advance in remote sensing image processing in the new 3D modeling method is remote sensing image registration with DEM. Registration of remote sensing image and DEM is the basis of 3D geomorphologic image mapping. To perform the superposition of remote sensing image data and DEM, it is necessary to carry out geometric registration and transform its coordinate space into a unified projection coordinate system after processing. In practice, the registration method based on control points is used to match the control points, estimate the geometric transformation parameters, and subsequently register the control points. Remote sensing image as texture data is mapped to the surface of the 3D model established by DEM data, which allows for realistic and objective simulation of the surface landscape. The spectral characteristics of remote sensing images can directly affect the visual effect of the stereo model. The accuracy of image and DEM nesting can determine the accuracy of 3D model reconstruction, thus playing an important role in improving the accuracy and fidelity of the whole 3D model. Three-dimensional terrain visualization takes the remote sensing image of a certain region as texture. DEM and remote sensing image are superimposed to ensure coordinate registration among different data, and text symbols, geographical elements, images, and other data from different sources of the same region are converted into the same coordinate system to form real-time 3D terrain of the region investigated [32]. The combination of remote sensing image and digital ground model includes three aspects: the generation of digital ground model from remote sensing image, the use of digital ground models to correct remote sensing images, and the registration application of remote sensing image and digital ground model [1].

\subsubsection{Remote sensing interpretation}

Remote sensing geoscience analysis requires the comprehensive integration of remote sensing and geographic information, and geoscience knowledge. Its purpose is to provide more visual information, dig deeper hidden space knowledge, and improve the accuracy of remote sensing image classification and thematic feature extraction. The development of space geodetic techniques is particularly important for the measurement of surface displacements, resulting in a dramatic increase in the number of deformable areas detected. [33-37] The combination of remote sensing image and digital ground model can be used in geological structure interpretation, geological prospecting, mine mapping, and surface subsidence monitoring, among others. [1] Remote sensing interpretation is mainly reflected in the following four aspects in geological aspects. 1) Up-and-down dislocation fault interpretation. Remote sensing data can be interpreted to reveal the faults on the exposed surface, and two parameters are mainly judged: the change of height difference and the difference of stratum properties. If the change of height difference is significant but there is no significant difference in the geotechnical properties, the fault can be considered as a potential fault with upper and lower disk dislocation. In this context, the Landsat-7 satellite was launched by NASA with an enhanced Thematic Mapper (ETM+) sensor. [38] Since landsat-7 ETM+ data are far superior to night light data and land cover data in terms of spatial resolution and spectral band richness, the extraction results can be used as a reference for future verification of various methods. [39,40] Therefore, Landsat can be used as the data source, which has the advantages of long-time sequence and high spatial resolution. [41] 2) Interpretation of horizontal dislocation fault. As the horizontal dislocation of geological and geomorphic bodies caused by strike-slip faults, this is also a relatively common fault structure. The displacement produced by this kind of horizontal dislocation has large range and time span. Horizontal 
dislocation faults can be judged by features such as ridge dislocation, synchronous asymmetry of river valley slope, and synchronous turning of river system and terrace. [42]

3) Multistage fracture interpretation. Multi-stage faults are characterized by complex faults formed by multistage tectonic movements, forming $\mathrm{t}$-shaped and $\mathrm{Y}$-shaped structural forms. The morphology of the outcrops is also particularly complex. One major technical procedure of multistage fault interpretation is to restore the geological body step by step to the state of no fault from ancient times through structural restoration, that is, through reverse engineering of faults. If the geological body cannot be recovered, a broken order should be attempted again until the correct or a better order is achieved. 4) Interpretation of remote sensing stratum structure. Remote sensing image assisted formation interpretation is also a common method of remote sensing image technology adopted in geology. By using multi-spectral remote sensing data analysis, various physical and chemical property parameters of the surface are obtained for comparison, and the existing geological map and characteristic data are referred to delineate the stratum boundary and distinguish the geological origin and geological age. In this case, the remote sensing image shows the tectonic trace and spatial framework of the crustal movement in a real, vivid, and intuitive way, thus providing the tectonic landscape image of multilayer, multi-scale, and multi-information source for regional tectonic geology research. Remote sensing tectonics analysis is a regional tectonics analysis research method based on modern tectonics theory and image tectonics information. Its main characteristic is that it allows for comprehensive analysis of the regional structure from surface to deep, from static to dynamic, from single information to multi-disciplinary information. [1] The fusion of geological model and remote sensing image data is shown in Figure 11.

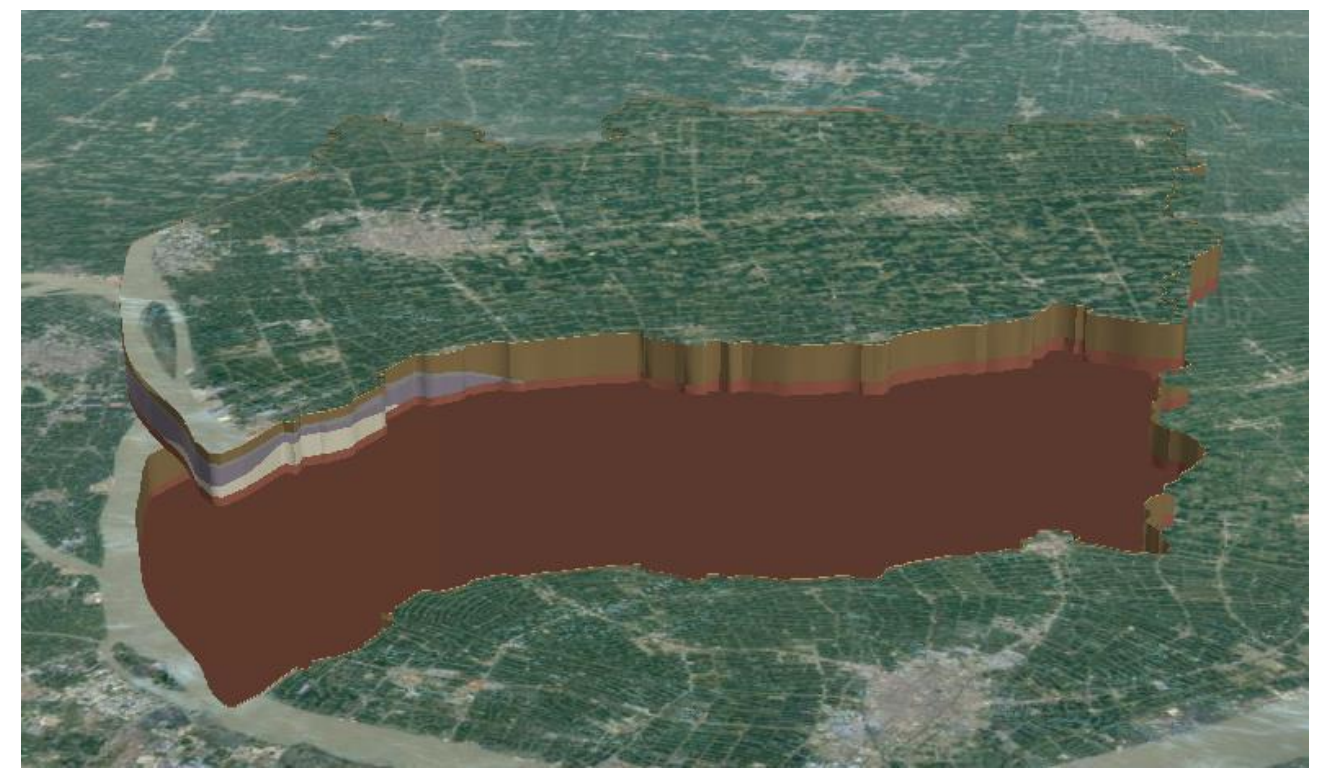

Figure 11. Fusion of geological model and remote sensing image data 1.7 Artificial building, DEM, and geological body cutting technology

The development and construction of cities has led to increased used of the underground space, which changes the shape of geological bodies. Therefore, to accurately describe the geological body and analyze and calculate the interaction between the man-made structure and the geological body, first, the cutting of the man-made 
structure on the geological body should be investigated. While many software models can cut man-made structures and geological bodies separately, few can cut the two with precision. However, a software of geological deep exploration based on the new 3D modeling method can be developed. The geological grid model after cutting is shown in Figure 12.

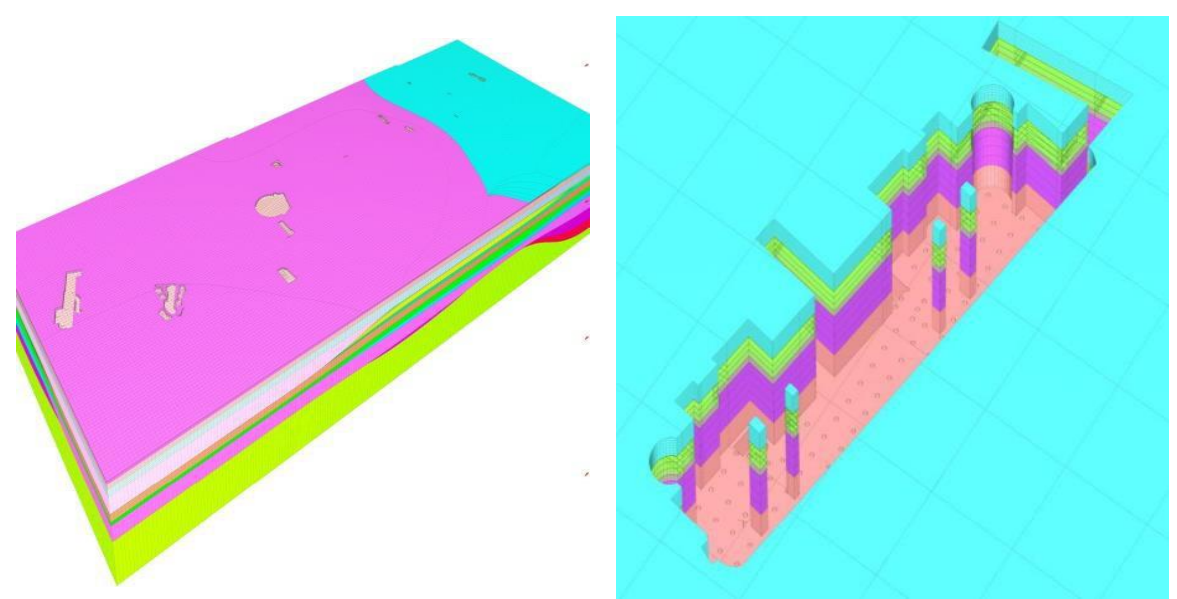

Figure 12. Geologic grid model after truncated by the main body of the building

The fusion of geological model and DEM data aims to solve the problem of mismatch between the precision of the geological model grid and DEM data. Overall, this refers to a problem of mismatch between high-precision DEM data and low-precision geological model grid. The method employed to solve this problem involves cutting the geological mesh with high precision DEM surface and forming a new complex polyhedral mesh on the DEM surface and geological body mesh.

\section{Application research of large-scale three-dimensional geological model}

\subsection{Overview}

The traditional large-scale 3D geological model can be adopted for simple long-time visualization because of its low precision. With the support of the new generation of 3D geological modeling technology, the application field of large-scale 3D geological modeling has been greatly expanded, enabling services for different needs on both macro and micro levels.

\subsection{Crustal stability analysis}

With the support of the new generation of 3D geological modeling technology, crustal stability analysis provides structural data of large regions and supports efficient structural information extraction. Integrating the monitoring data involved in the evaluation, analysis, and calculation of crustal stress stability into the geological model can provide not only intuitive stratigraphic correlation for crustal stability investigation, but support for crustal stress stability analysis and calculation mathematical model for stress simulation and prediction analysis.

\subsection{Evaluation of geological suitability}

The integral structure modeling technique plays an important role in supporting suitability evaluation in large- 
scale engineering geology. Integration can be achieved under the foundation and architecture of the whole construction model. As an integrated platform for multidisciplinary staff collaboration, it can meet the needs of evaluation in both dimensions of scale and precision. Multi-source heterogeneous data processing technology provides an accurate geological model for the evaluation work. The establishment of an attribute model provides a large amount of spatial attribute data for the evaluation project and supports quantitative evaluation.

\subsection{Analysis and research of geological big data mining}

Remote sensing image data mining is used to discover and mine the information hidden in remote sensing image by using data image analysis, pattern recognition, artificial intelligence, geographic information system, and spatial data mining, among other methods. It is also an application of image data mining technology in the remote sensing field. This emerging technology involves several disciplines, such as image processing, spatial database, spatial data analysis, expression and visualization, spatial data mining, geographic information technology, information extraction, machine learning, and software design [43]. Geological big data mining and analysis technology is a research hotspot in the field of geology. As machine learning technology has matured over time, its most fundamental requirement is currently to establish a set of deep neural networks. A deep neural network predicts the change in geological body movement and the distribution of underground minerals through the geological body structure and attribute distribution data. The attribute model provides a unified storage and management function for the geological body structure and attribute distribution data, and can well support various types of geological big data analysis.

\subsection{Study and application of seismically active faults}

Active fault is a major object of seismic research. However, scarce research on geological structure environment and deep strata movement would restrict further research on active faults. Most active areas have complex surface deformation patterns caused by a variety of natural factors (such as expansion, contraction, dike invasion, active fault, lateral instability, and landslide) and human factors (such as local uplift or subsidence) [44]. If the detailed data of active fault research can be applied to 3D geological modeling, the accuracy of active fault description of geological model can be greatly improved. The location, form, and geological risks of active faults receive considerable attention not only in earthquake research, but also in geological disaster prevention and control, urban planning, and construction activities. Over the past few decades, the quantity and quality of geodetic data have expanded and improved. These data have been increasingly applied to the study of both geological and man-made disasters [45-51]. As the carrier of geological information, the 3D geological model can not only effectively undertake the information fusion of overground and underground integration, but also provide services for users of active faults more effectively. For example, active faults have great influence on the formation and activity of debris flow. In the past, due to the concealed characteristics of the fault itself, there was a lack of research on the fault activity law and the difference of its influence on the surface. This makes it difficult not only to quantify the impact of active faults on debris flow, which represent the effect of earth's internal forcings, but also to accurately and rationally consider the impact of active faults in the current debris flow risk assessment [52]. More accurate debris flow risk assessment results can be obtained by integrating the 
research results of active faults with the 3D geological model.

\section{An application example of 3D geological modeling in the Ya'an Area}

\subsection{Overview}

The Ya'an area of Sichuan province is located in southwest China, spanning the Sichuan Basin and the QinghaiTibet Plateau. It comprises an extensive area and complex geological conditions. Ya'an city has 56 types of known mineral species, with 620 mineral producing areas, in addition to 30 types of minerals with proven reserves of mineral resources. Considering the implementation of a major construction project in this area, the Ya'an section of Sichuan-Tibet Railway is expected to establish a large-scale, high-precision three-dimensional geological model covering the Chengdu and Changdu maps based on existing geological data. The model can support the evaluation of geological adaptability of engineering construction, geological environment protection, and geological disaster prevention and control in this area.

\subsection{Overview of the Modeling Scheme}

Three-dimensional geological modeling of the Ya'an Area was conducted with four angular coordinates (longitude: 101.522194, latitude: 29.95286), (longitude: 103.008852, latitude: 29.95286), (longitude: 103.008852, latitude: 28.007564), and (longitude: 103.008852, latitude: 28.007564). The new 3D geological modeling method was adopted in this modeling. Based on the theories of geology and related disciplines, the main structural features, such as topographical features, soil-rock interface, lithologic boundary, lithologic association, fault, fold, and structural plane, as well as the inland layer distribution and structural morphology within a certain depth range, were investigated and evaluated in the Ya'an area. The spatial distribution and variation of the surface and underground geological bodies were mastered in detail. Based on new research and development of 3D modeling methods of geological deep investigation software, more drilling, geological mapping, and remote sensing image data source integration, large-scale integrated modeling technology was adopted to construct in large-scale high precision and the whole geological model of multi-resolution modeling using grid subdivision and multi-attribute model is set up, in addition to a geological 3D visualization model of the Ya'an area for geological research, comprising geological suitability evaluation work with 3D geological data services. The technical route is shown below (Figure 13). 

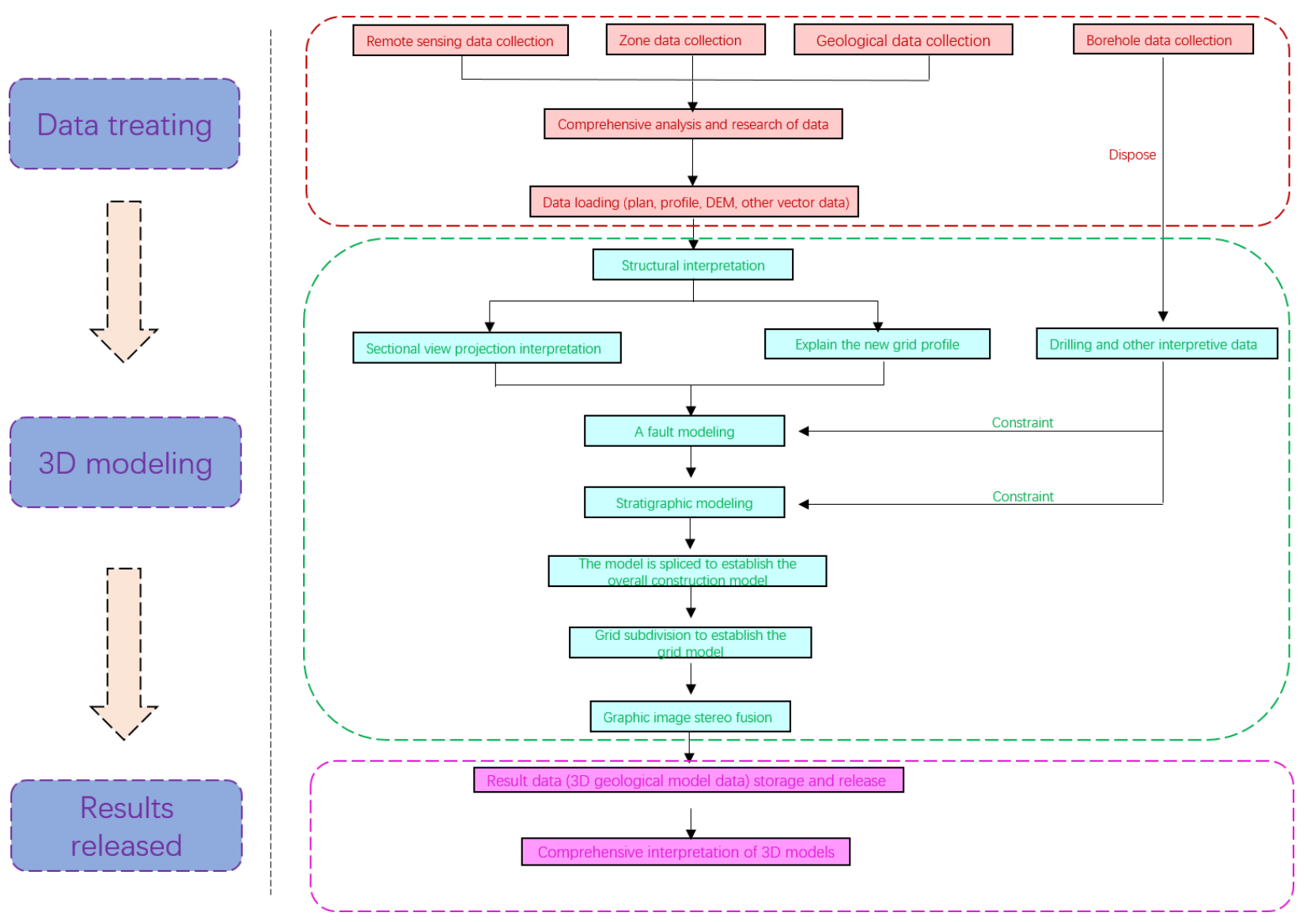

Figure 13. Roadmap of new 3D geological modeling technology

\subsection{Data source situation}

\subsubsection{Borehole stratification data}

The modeling used stratified data, such as basic geological age and stratigraphic group, of nearly 1500 borehole columns in the area, with borehole depths ranging from 20 to 650 meters. Some drilling stratification data are shown in Table 2. 
Table 2 Sample stratified data of boreholes

\begin{tabular}{|c|c|c|c|c|c|c|}
\hline \multirow{2}{*}{$\begin{array}{l}\text { Borehole } \\
\text { Number }\end{array}$} & \multirow{2}{*}{$\begin{array}{c}\text { Layer } \\
\text { number }\end{array}$} & \multicolumn{2}{|c|}{ Layered depth } & \multirow{2}{*}{ Thickness } & \multirow{2}{*}{ Date on the drill column } & \multirow{2}{*}{ Formation } \\
\hline & & From & To & & & \\
\hline $13-2$ & 1 & 0 & 1.6 & 1.6 & $P t d^{5-1-2-(三)}$ & \\
\hline $13-2$ & 2 & 1.6 & 132.76 & 131.16 & $E$ & Jiujitan \\
\hline $13-2$ & 3 & 132.76 & 288.8 & 156.04 & $\in$ & Yulongshan \\
\hline $13-2$ & 4 & 288.8 & 299.97 & 11.17 & $\in$ & Yulongshan \\
\hline $13-2$ & 5 & 299.97 & 364.61 & 64.64 & $\in$ & Changxing \\
\hline $13-2$ & 6 & 364.61 & 366.61 & 2 & $\in$ & Longtanmei \\
\hline $13-2$ & 7 & 366.61 & 369.37 & 2. 76 & $E$ & Longtanmei \\
\hline $13-2$ & 8 & 369.37 & 371.2 & 1. 83 & $\in$ & Longtanmei \\
\hline $13-2$ & 9 & 371.2 & 375.38 & 4. 18 & $\in$ & Longtanmei \\
\hline $13-2$ & 10 & 375.38 & 376.83 & 1. 45 & $\in$ & Longtanmei \\
\hline $13-2$ & 11 & 376.83 & 380.64 & 3. 81 & $\in$ & Longtanmei \\
\hline $13-2$ & 12 & 38.64 & 384.02 & 3. 38 & $E$ & Longtanmei \\
\hline $13-2$ & 13 & 384.02 & 384.94 & 0.92 & $\in$ & Longtanmei \\
\hline $13-2$ & 14 & 384.94 & 387.04 & 2. 1 & $\in$ & Longtanmei \\
\hline $13-2$ & 15 & 387.04 & 390.64 & 3.6 & $\in$ & Longtanmei \\
\hline $13-2$ & 16 & 390.64 & 395.32 & 4. 68 & $\in$ & Longtanmei \\
\hline $13-2$ & 17 & 395.32 & 396.39 & 1. 07 & $\in_{1} \mathrm{j}$ & Longtanmei \\
\hline $13-2$ & 18 & 396.39 & 408.59 & 12.2 & Anz & Longtanmei \\
\hline $13-2$ & 19 & 408.59 & 411. 4 & 2.81 & $\mathrm{~F}$ & Longtanmei \\
\hline $13-2$ & 20 & 411. 4 & 414. 25 & 2.85 & $\mathrm{~F}$ & Longtanmei \\
\hline $13-2$ & 21 & 414.25 & 416.5 & 2. 25 & $\mathrm{~F}$ & Longtanmei \\
\hline $13-2$ & 22 & 416.5 & 417.21 & 0.71 & $\mathrm{~F}$ & Longtanmei \\
\hline $13-2$ & 23 & 417.21 & 421.7 & 4. 49 & $\mathrm{~F}$ & Longtanmei \\
\hline
\end{tabular}

\subsubsection{Geological map data}

A 1:100,000 map of Chengdu and a map of Changdu were used in this modeling, as shown in Figure 14 below. The modeling area is in the mosaic area of two maps, as shown in Figure 15. The modeling area covers 311,04 square kilometers belonging to the edge of Sichuan Basin, which has significant terrain differences and particularly complex structures. It is mainly composed of deep hills and mountains, with the elevation mostly between 1,000-3,000 meters and the relative elevation difference around 1,000 meters. 


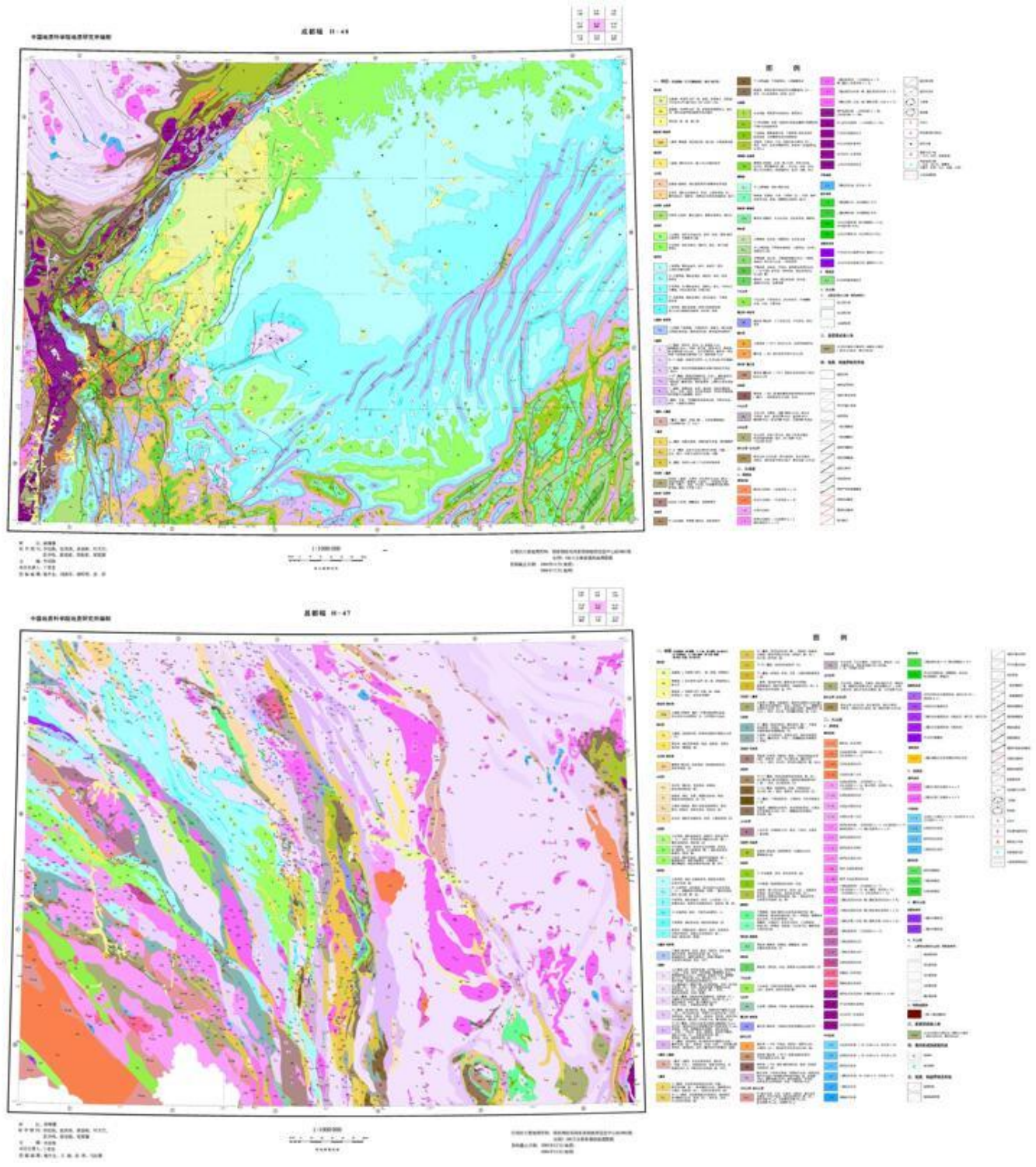

Figure 14. 1:100,000 scale geological map of Chengdu and Changdu

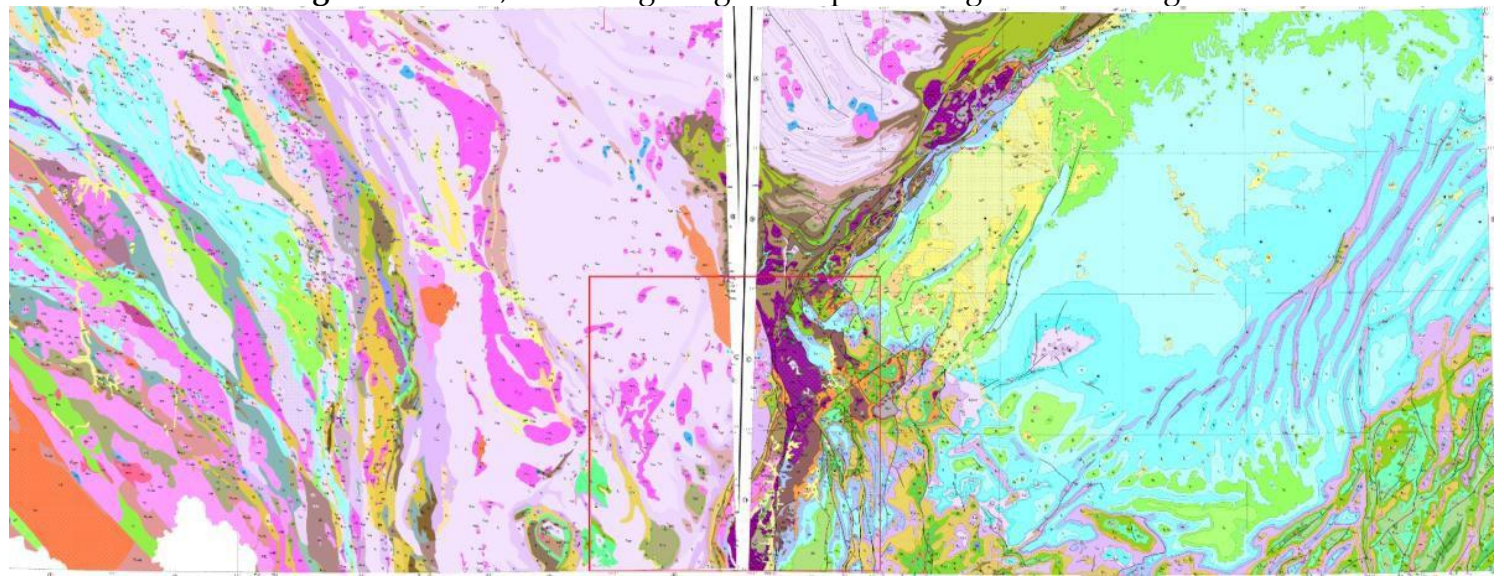

Figure 15. Work area - geological map of Chengdu and Changdu 


\subsubsection{Remote sensing image data}

High-precision remote sensing image data of the Ya'an area were adopted in this modeling, as shown in Figure 16 below. It is used for modeling reference in the early stage and visualization of surface integration of 3D models in the later stage to assist the geological research in this area. Remote sensing images can objectively reflect the morphology, structure and spatial relationship of scenery and other features, so that people have a macroscopic and overall understanding of ground objects. It is generally believed that the higher the spatial resolution, the better the data $[53,54]$. High quality land cover data products, such as high-resolution optical remote sensing images, are important data sources for surface information extraction [55-61]. At the same time, it can truly and objectively record and reflect the surface scene, which is an important data resource for 3D terrain simulation.

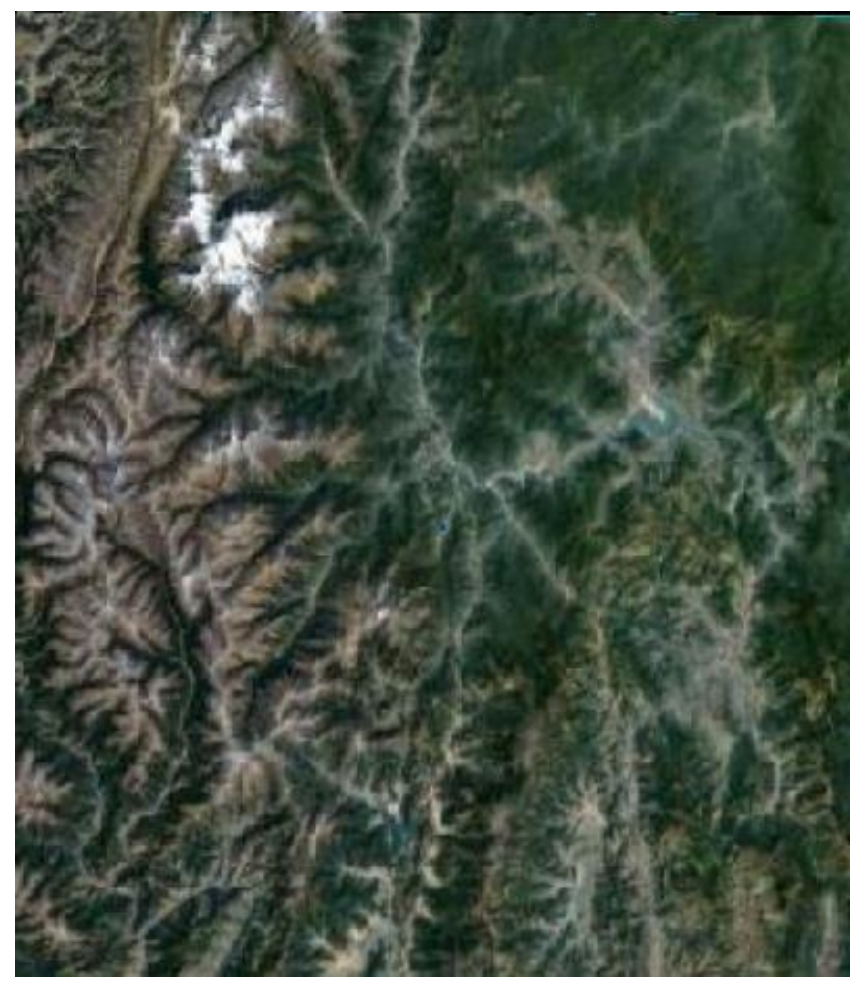

Figure 16. High precision satellite image data in Ya 'an area

\subsubsection{Data organization}

The borehole data are arranged into a unified data format, and the stratified points are arranged into three sets of stratified data according to generation, system, and period, respectively. It is used to build models with different ranges and precision to solve the problem of too large and too thin layers in the work area. The borehole position data is transformed from WGS84 coordinate system projection to China 2000 coordinate system, and the projection type is Gauss-Kruger projection. Regarding organization of map data, to ensure the consistency of the projection parameters with the borehole, the 1:100000 Chengdu and Changdu frames are projected into the Chinese coordinate system of 2000. As for organization of the furface elevation data, 90 meters of resolution data were downloaded from the geospatial data cloud for cropping and thinning. The raster is rotated 
first, and then the data is projected to the Chinese 2000 coordinate system. After importing the surface elevation data and borehole data into the geotechnical deep exploration software, they are simultaneously displayed. The good match between them indicates that the projection is correct, as shown in Figure 17 below. After importing the surface elevation data, borehole data and map boundary data into the geotechnical deep exploration software, the three data are well matched, indicating that the projection is correct, as shown in Figure 18 below.

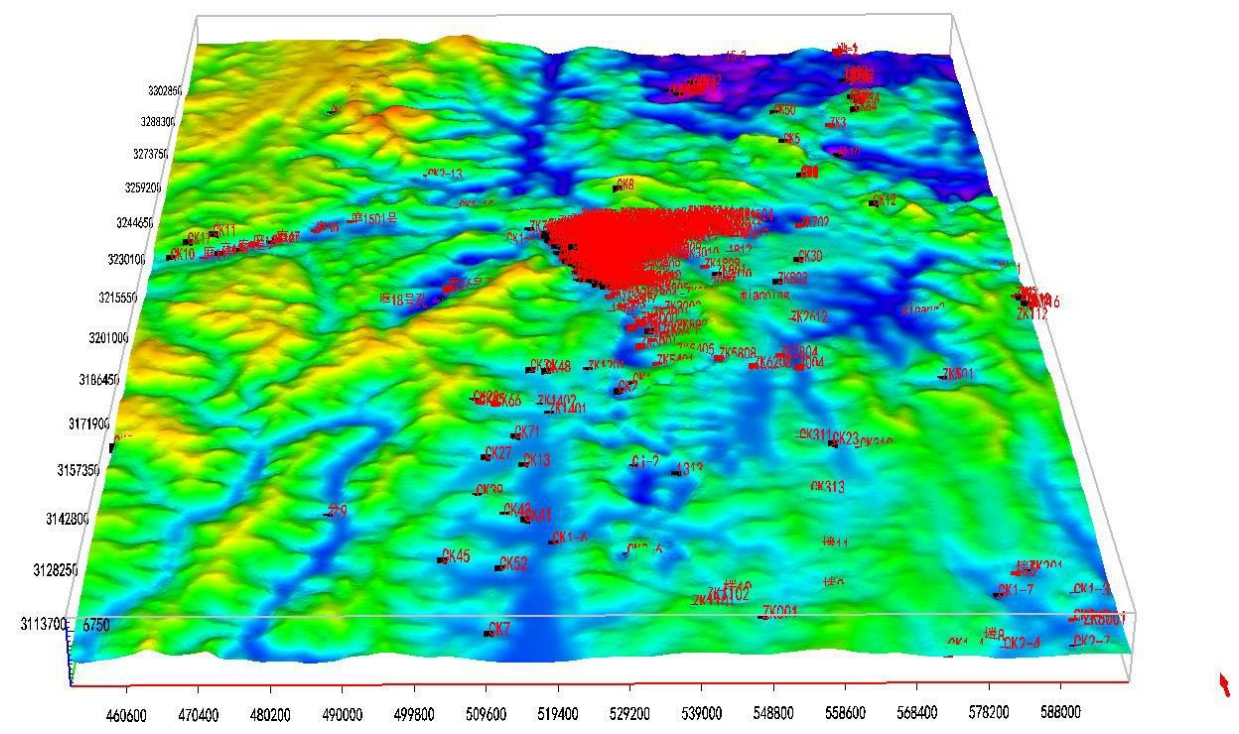

Figure 17. Surface elevation and borehole matching renderings

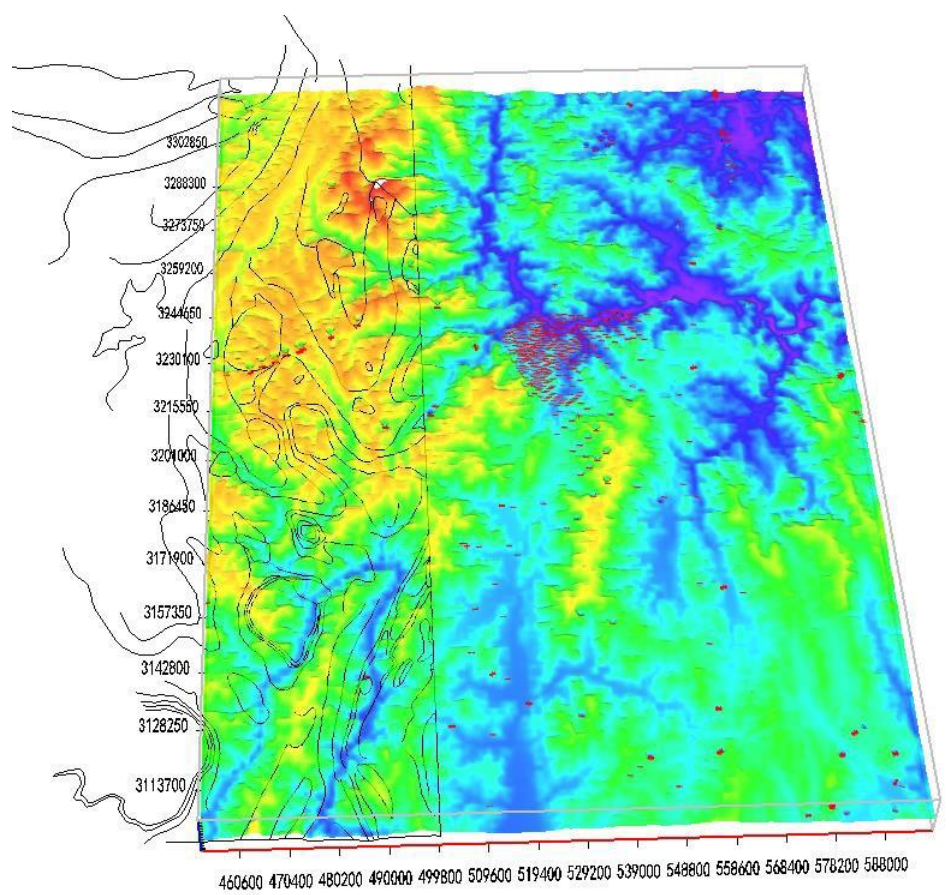

Figure 18. Matching renderings of surface elevation, borehole and map boundary 


\subsubsection{Difficulties}

First, the scale of work area is too large, which leads to the increase in the number of modeling grids, thus leading to a significant increase in computational complexity. Second, the horizontal and vertical proportions are not coordinated, with $144,383 * 215,944$ meters in the horizontal direction, while the thickness of the layers of the longitudinal borehole varies from several meters to ten meters, and the depth of the final hole is less than 4,000 meters. Third, the distribution of modeling data is not uniform, and the borehole data is concentrated in an internal minimal area, as shown in Figure 19. As a result, the regional layers where the borehole is concentrated are very steep, while the data constraints of other regional layers are not enough, resulting in problems such as layer penetration. Fourth, the coordinate system of data is not unified.

Coordinate systems with different attributes are applied to the data: the borehole data is WGS84 coordinate system, while the Chengdu and Changdu maps are Beijing 54 coordinate system, and the projection type is Lambert isometric cone. Finally, in the same project, strata and intrusive rocks are alternately distributed in the same borehole. In the large model, the topmost strata data and the bottommost intrusive rocks data are used.

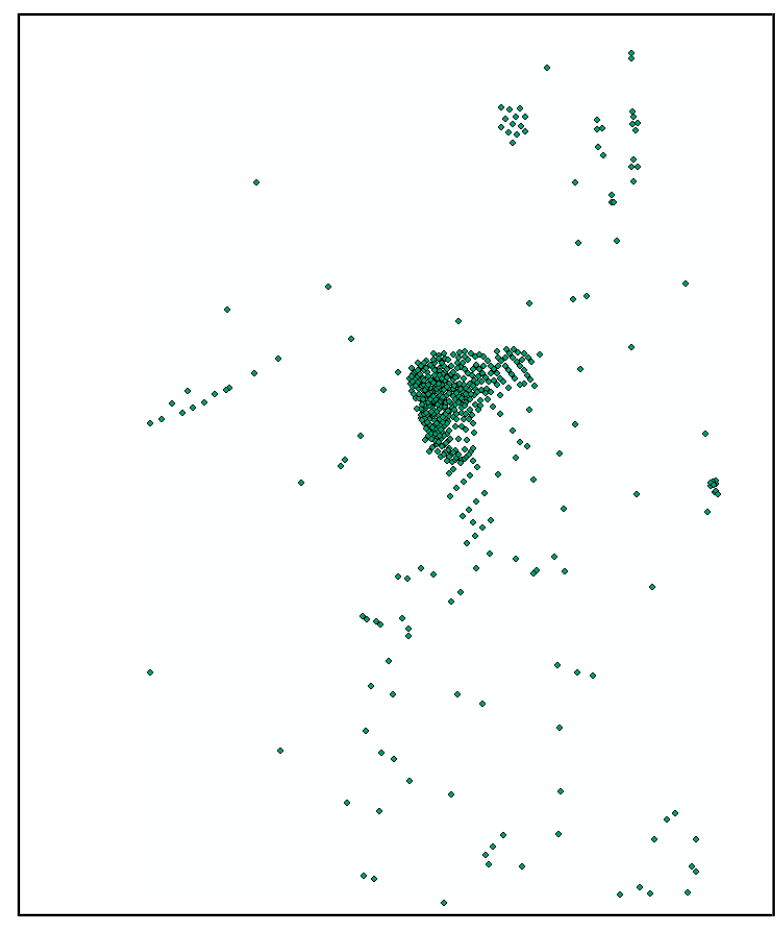

Figure 19. Modeling borehole distribution diagram

\subsection{Project results}

3.4.1 Large scale and high precision model based on multivariate data

Using a new $3 \mathrm{~d}$ geological modeling method based on remote sensing technology, the overall structure modeling of the Ya'an area is carried out. The $3 \mathrm{~d}$ geological modeling data used drilling, geological map, remote sensing 
and other data. After the four steps of multi-source heterogeneous data processing, large-scale high-precision modeling, grid subdivision and attribute modeling, the modeling accuracy reaches $50 \mathrm{~m}$ grid precision and $50 \mathrm{~m}$ fault grid. Because the modeling area is large, the modeling process adopts large-scale overall high-precision modeling technology. First, it is divided into 4 pieces for independent modeling. Then the four independent models are seamlessly spliced together to complete the underground 3D geological model. Finally, through OpenGL 3D rendering technology and stacking inclined photographic model, a 3D geological model is built, as shown in Figure 20 below.

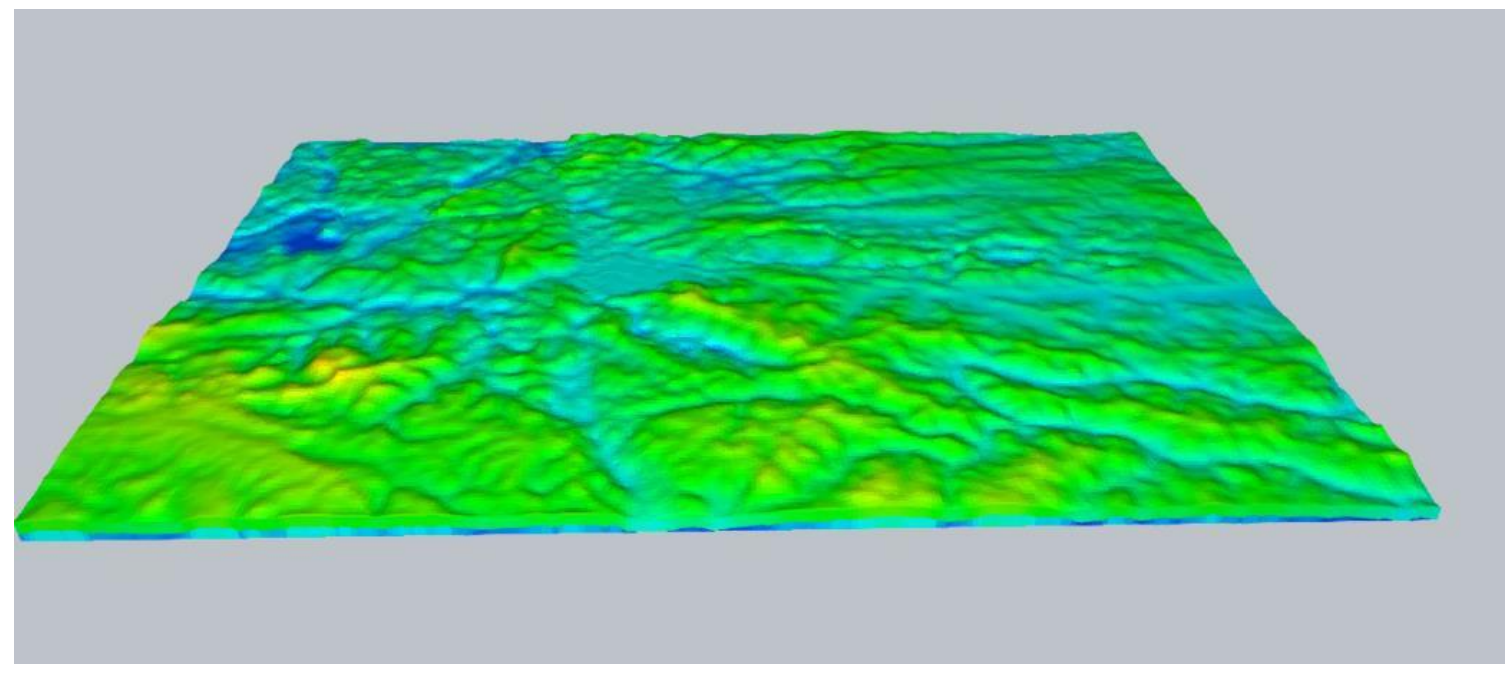

Figure 20. Results of 3D geological model in Ya 'an Area

\subsubsection{Visual geological study of remote sensing image fusion}

Due to the complexity and irregularity of surface landscape, simple texture mapping technology is difficult to obtain satisfactory results. By processing remote sensing images and sticking them on the $3 \mathrm{~d}$ terrain surface as texture images, the sense of reality of 3D terrain simulation can be greatly improved [7]. Using remote sensing image and DEM to apply surface texture mapping to 3D terrain simulation can effectively improve the sense of reality of simulation visualization. Superimposing DEM data and remote sensing image to generate 3D image can not only vividly reflect the terrain and geomorphological features of this region, but also reproduce the landscape features of this region. This has a good application prospect for $3 \mathrm{~d}$ visualization in landscape areas with inconvenient traffic and sparsely populated [7]. Three-dimensional modeling in the Ya'an region combines remote sensing image and geological model as shown in Figure 21 below. It can provide interactive functions such as cutting and excavation for geological research. At the same time, it can provide support for judging whether the geological structure of the 3D model is reasonable, whether the division of sedimentary areas is accurate, whether the description of geotechnical properties is accurate and so on. 

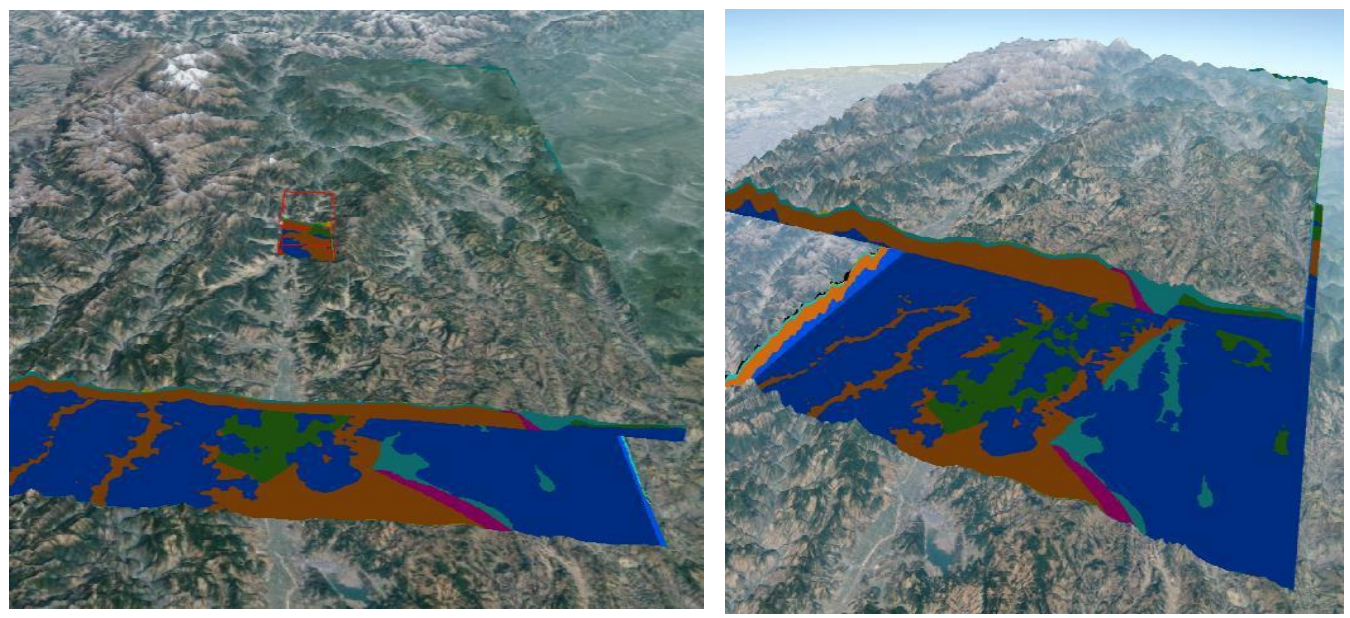

Figure 21. Interaction study of remote sensing image fusion

\subsubsection{Constrained subdivision grid model based on structural model}

Based on the constraints of the structural model, the volume grid is subdivided and the grid is a truncated rectangular grid. Using this grid division technique, the grid model and the structural model are highly consistent in geometry, and the grids remain smooth at both the stratum and the fault layer, as shown below Figure 22 . The grid model is a multi-precision model and supports multiple resolutions of grids, which can well support LOD pattern visualization.

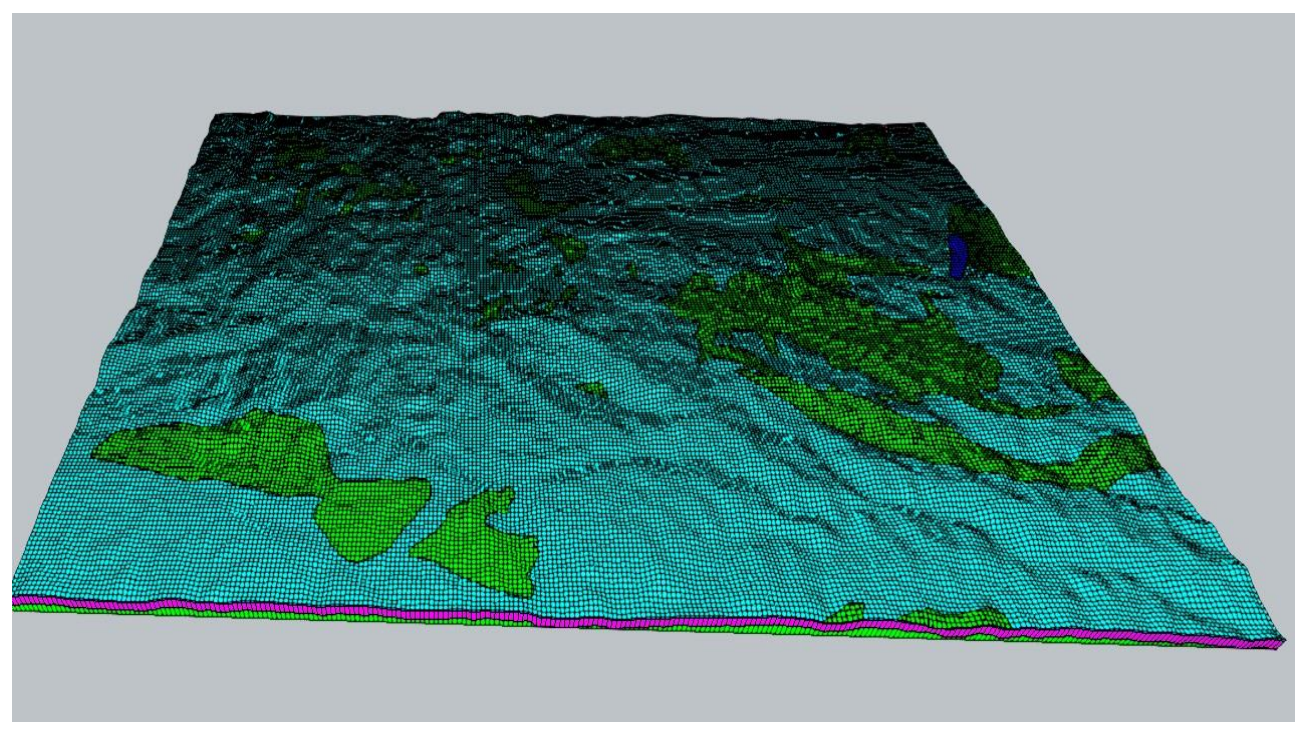

Figure 22. Grid model with structural constraints

\subsubsection{Multi-attribute model}

Based on the grid model and using the geostatistical interpolation method, the high-precision attribute models of lithology, porosity and permeability were established in some areas of this project based on the borehole attribute information, as shown in Figure 23 below. 


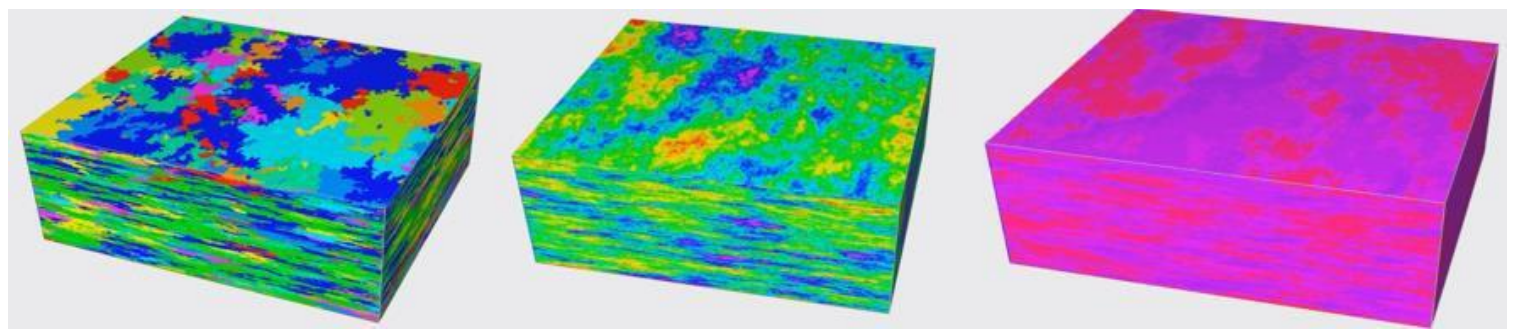

Figure 23. Results of local high-precision attribute model

The high-precision attribute model can support the query service of geological data (including attributes) in this area. It can provide detailed and authoritative data for regional planning, engineering construction, scientific research, underground resource assessment and other work. Another important advantage of the attribute model is the low cost of updating, unlimited extension of the attribute capacity, and long-term sustainable services.

\subsubsection{Remote sensing image interpretation of faulted structures}

After the spatial coordinate transformation, the large-scale high-precision model and the remote sensing image are fused seamlessly, and the two models are in perfect agreement. This indicates that the modeling accuracy is very high, and the results are shown below (Figure 24).

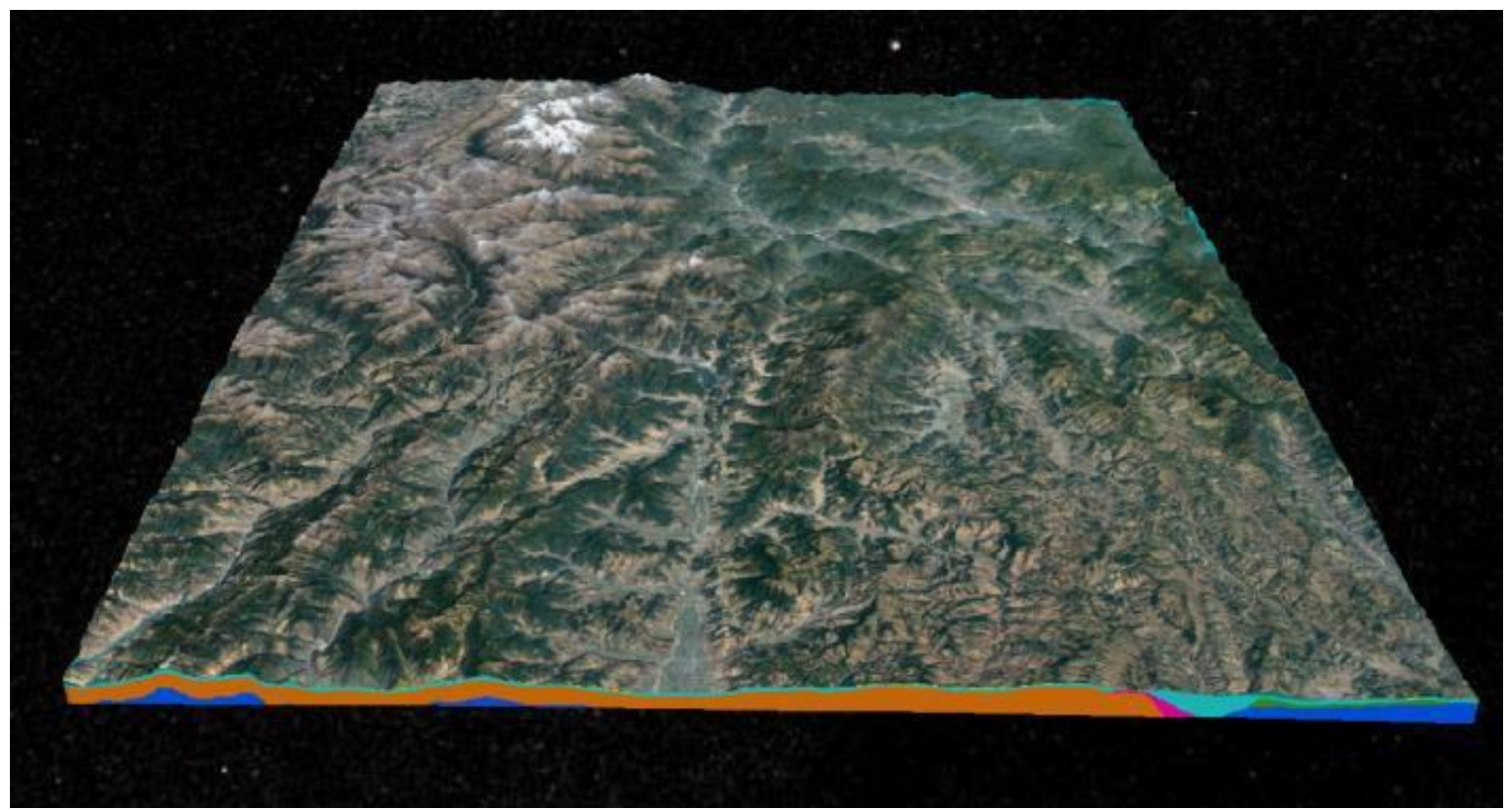

Figure 24. Fusion of remote sensing images and geological models

In this project, remote sensing images were used for fault interpretation, and new potential faults were found, as shown in Figure 25 red line. The potential fault structure starts at the point (longitude: 102.2267, latitude: 28.5761) and ends at the point (longitude: 101.8865, latitude: 28.3011). 


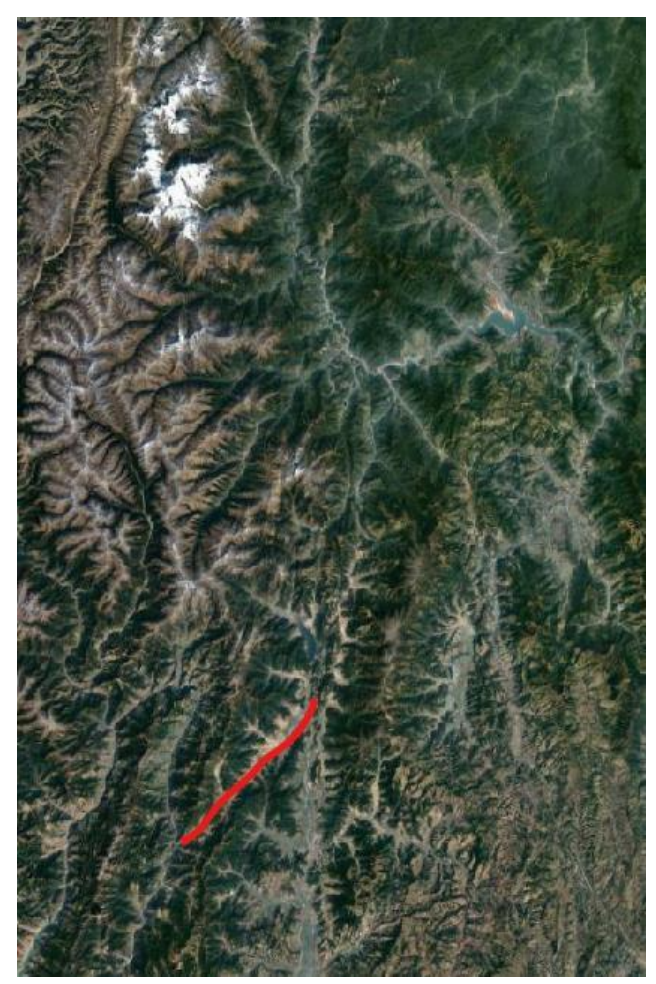

Figure 25. Remote sensing interpretation of fault structure

Through the comparison of high-precision remote sensing elevation information, the average distance difference between the two sides of the potential fault is determined to be 95 meters, and the average fault distance of the potential fault is preliminarily determined to be 95 meters. Along the direction of the fault line, the north side is higher and the south side is lower. At the same time, by referring to the fracture tendency of the same strike nearby, it is preliminarily judged to be a reverse fracture with a southeast tendency of $45^{\circ}$ dip Angle of $78^{\circ}$. This interpretation has been applied to the construction modeling of this project.

\subsubsection{Comprehensive application of remote sensing image interpretation and 3D geological model}

The results of remote sensing image analysis can be segmented and segmented by the 3D integral model constructed in this paper. It can not only see the geological subsurface structure and occurrence, but also verify whether the interpretation results of remote sensing images are correct. The comprehensive application of remote sensing and geological modeling technology has not only greatly promoted the progress of earth science, but also pushed the application of remote sensing technology to a new height.

\section{$4 \quad$ Summary and Prospect}

Remote sensing technology provides a new data source and a way to explore the earth for geoscience applications [1]. The whole structure modeling practice in the Ya'an area makes us deeply realize the importance of the new 3D geological modeling method based on remote sensing technology. The multi-source heterogeneous data modeling technology, especially the comprehensive application of remote sensing image data and remote sensing technology, not only greatly improves the application degree of geological data, but also maximally improves the accuracy of 3D geological model. This also lays a solid foundation for the 
application of geological model. It is convenient to realize the integration of geological data through large-scale integral modeling technology and the establishment of model database. Through grid subdivision and attribute modeling, the attribute model is established in this region for the first time. The attribute model can accommodate all kinds of geological attributes and provide discrete data support for quantitative big data geological research. Looking forward to the development of 3D geological modeling technology, it should focus on two centers. One is to reduce the cost of user modeling and improve the efficiency of modeling. The second is to improve the quality of the model to better and more comprehensively meet the needs of all kinds of users. In order to meet the first goal, artificial intelligence and machine learning technologies should be used to replace the artificial links (such as section interpretation model editing) that currently affect the efficiency of 3D modeling. In addition, cloud computing and parallel computing technologies are introduced to reduce the time consumption and improve the efficiency of modeling. It is an important technical route to combine remote sensing interpretation with artificial intelligence. The existing geological maps, especially high-precision geological maps and remote sensing data, are matched as the big data foundation of machine learning. On this basis, a deep neural network is established to characterize remote sensing image features and geological structure features, so as to expand remote sensing image data into an important data source for basic geological survey and regional geological survey. In order to meet the second goal, surface modeling algorithm, mesh generation technology and attribute modeling technology should be continuously improved. At the same time, numerical simulation methods suitable for large-scale geological models were developed, and more technologies were developed in the fields of ground stress simulation, groundwater seepage simulation, fluid pressure simulation and so on.

The Physical Geological Data Center of Natural Resources has established a service platform for important geological borehole data, and has released 1.1 million important geological borehole data to the public through geological cloud. The 1.1 million drill holes have a total footage of 275 million $\mathrm{km}$, covering 31 provinces nationwide. Combined with remote sensing images, this new modeling method can be used to draw a complete and detailed three-dimensional display of the national underground surface. This will make a great contribution to geologists and other researchers from all over the country and the world. For other problems encountered in the future, we will track improvement from the technical and method.

\section{Declarations}

Author Contributions: Conceptualization, Z.M., L.Z.; data curation, Z.M.; formal analysis, Z.M.; funding acquisition, L.Z.; investigation, Z.M., L.Z., Y.W.; methodology, Z.M. , G.Z , Y.W.; project administration, Z.M., Y.W.; resources, L.Z.; software, Z.M., L.Z., Y.W.; supervision, Z.M. and Y.W.; validation, Z.M., Y.W.; visualization, Z.M., Y.W.; writing - original draft, Z.M. , Y.L. ,L.Z.; writingreview \& editing, Z.M., Y.W. All authors have read and agree to the published version of the manuscript.

Funding: This research was jointly Supported by the Geological Survey Project of China Geological Survey, "National Data Updating and Service of Geological Drilling" (No.: DD20190410).

Acknowledgments: We gratefully acknowledge the reviewers for their insightful comments of the manuscript, thank other team members for help with the experiment.

Conflicts of Interest: The authors declare no conflict of interest. 


\section{References}

1. Ling H (2005) Research on Multi-Source Remote Sensing Information Fusion Technology and Application of Multi-Source Information in Geoscience. Northwestern University.

2. Research on generating contour lines of coal mine gas geological map based on ArcGIS. Yi-hui Yang; Mine Survey, 2013-04-15

3. Masterlark T (2007) Magma intrusion and deformation predictions: sensitivities to the Mogi assumptions. J Geophys Res 112:B06419. https://doi.org/10.1029/2006JB004860

4.Long SM, Grosfils EB (2009) Modeling the effect of layered volcanic material on magma reservoir failure and associated deformation, with application to Long Valley Caldera, California. J Volcanol Geotherm Res 186:349_ 360. https://doi.org/10.1016/j.jvolgeores.2009.05.021

5.Castaldo R, Gola G, Santilano A, De Novellis V, Pepe S, Manzo M, Manzella A, Tizzani P (2017) The role of thermorheological properties of the crust beneath Ischia island (Southern Italy) in the modulation of the ground deformation pattern. J Volcanol Geotherm Res 344:154-173. https://doi.org/10.1016/j.jvolgeores.2017.03.003

6. Horning N (2008) Remote sensing. In: Encyclopedia of Ecology. Elsevier, Amsterdam, The Netherlands.

7. Slonecker ET, Jennings DB, Garofalo D (2001) Remote sensing of impervious surfaces: a review. Remote Sens Rev 20:227-255. https://doi.org/10.1080/02757250109532436

8. Balsamo G, Agusti-Panareda A, Albergel C, Arduini G, Beljaars A, Bidlot J, Blyth E, Bousserez N, Boussetta S, Brown A, Buizza R, Buontempo C, Chevallier F, Choulga M, Cloke H, Cronin MF, Dahoui M, De Rosnay P, Dirmeyer PA, Drusch M, Dutra E, Ek MB, Gentine P, Hewitt H, Keeley SPE, Kerr Y, Kumar S, Lupu C, Mahfouf J, McNorton J, Mecklenburg S, Mogensen K, Muñoz-Sabater J, Orth R, Rabier F, Reichle R, Ruston B, Pappenberger F, Sandu I, Seneviratne SI, Tietsche S, Trigo IF, Uijlenhoet R, Wedi N, Woolway RI, Zeng X (2018) Satellite and in situ observations for advancing global Earth surface modelling: a review. Remote Sens 10:2038. https://doi.org/10.3390/rs10122038

9. Schowengerdt RA (2007) Remote Sensing. Elsevier, Amsterdam, The Netherlands.

10.Salamí E, Barrado C, Pastor E (2014) UAV Flight Experiments Applied to the Remote Sensing of Vegetated Areas. Remote Sens 6:11051-11081. https://doi.org/10.3390/rs61111051

11. Räsänen A, Virtanen T (2019) Data and resolution requirements in mapping vegetation in spatially heterogeneous landscapes. Remote Sens Environ 230. https://doi.org/10.1016/j.rse.2019.05.026

12. Yao H, Qin R, Chen X (2019) Unmanned aerial vehicle for remote sensing applications - a review. Remote Sens 11:1443. https://doi.org/10.3390/rs11121443

13. Calsamiglia A, Gago J, Garcia-Comendador J, Bernat JF, Calvo-Cases A, Estrany J (2020) Evaluating functional connectivity in a small agricultural catchment under contrasting flood events by using UAV. Earth Surf Process Landforms 45:800-815. https://doi.org/10.1002/esp.4769

14. Matese A, Toscano P, Di Gennaro S, Genesio L, Vaccari F, Primicerio J, Belli C, Zaldei A, Bianconi R, Gioli B (2015) Intercomparison of UAV, aircraft and satellite remote sensing platforms for precision viticulture. Remote Sens 7:2971-2990. https://doi.org/10.3390/rs70302971

15. Chen Y, Guerschman JP, Cheng Z, Guo L (2019) Remote sensing for vegetation monitoring in carbon capture storage regions: a review. Appl Energy 240:312-326. https://doi.org/10.1016/j.apenergy.2019.02.027

16.Xue J, Su B (2017) Significant remote sensing vegetation indices: a review of developments and applications. J Sens 2017:1-17. https://doi.org/10.1155/2017/1353691,

17. Wang RS (2011) Remote Sensing geological Exploration Technology and Application Research. Acta Geogr Sin 85:1699-1743

18. Xiaofeng D (2018) Research on Lithology Supervision Classification based on Resource 3 Satellite Image. Resour Environ Eng 032:291-295

19.Ge W, Yang H, Zhu X, Ma M, Yang Y (2018) Ghost city extraction and rate estimation in China based on NPPVIIRS night-time light data. ISPRS Int J Geo Inf 7:219. https://doi.org/10.3390/ijgi7060219

20. Tolpekin VA (2014) Detection of built-up area in optical and synthetic aperture radar images using conditional random fields. J Appl Remote Sens 8:083672.

21.Bhaskaran S, Paramananda S, Ramnarayan M (2010) Per-pixel and object-oriented classification approachs for 
mapping urban features using Ikonos satellite data Appl Geogr 30:650-665. https://doi.org/10.1016/j.apgeog.2010.01.009

22. Min H (2014) Discussion on genetic Correlation between Huashan rock mass and Gupaishan rock mass based on comparative analysis of remote sensing image characteristics of fault structure. Remote Sens Land Resour 26:162-169

23.Xiaochun L (2005) Multi-Source Remote Sensing Image Fusion Technology and Application Research. PLA University of Information Engineering

24. Song J, Tong X, Wang L, Zhao C, Prishchepov AV (2019) Monitoring finer-scale population density in urban functional zones: A remote sensing data fusion approach. Landsc Urban Plan 190:103580. https://doi.org/10.1016/j.landurbplan.2019.05.011

25.Stevens FR, Gaughan AE, Linard C, Tatem AJ (2015) Disaggregating census data for population mapping using random forests with remotely-sensed and ancillary data. PLOS ONE 10:e0107042. https://doi.org/10.1371/journal.pone.0107042

26. Levin N, Duke Y (2012) High spatial resolution night-time light images for demographic and socioeconomic studies. Remote Sens Environ 119:1-10. https://doi.org/10.1016/j.rse.2011.12.005

27. Li XM, Zhou WQ (2018) Dasymetric mapping of urban population in China based on radiance corrected DMSPOLS nighttime light and land cover data. Sci Total Environ 643:1248-1256. https://doi.org/10.1016/j.scitotenv.2018.06.244

28. Wasklewicz T, Staley DM, Reavis K, Oguchi T (2013) 3.6 Digital terrain modeling. In: Shroder JF (ed.) Treatise on Geomorphology. Academic Press, San Diego, CA, pp 130-161. https://doi.org/10.1016/B978-0-12-3747396.00048-8

29. Zhang W, Qi J, Wan P, Wang H, Xie D, Wang X, Yan G (2016) An easy-to-use airborne LiDAR data filtering method based on cloth simulation. Remote Sens 8:501. https://doi.org/10.3390/rs8060501

30. Rott H, Cihlar J, Schaepman ME, Garc í a-Santos G, Fernandes R, Berger M (2012) Sentinels for science: Potential of Sentinel-1, -2, and -3 missions for scientific observations of ocean, cryosphere, and land. Remote Sens Environ 120:91-101.

31. Woodcock CE, Allen R, Anderson M, Belward A, Bindschadler R, Cohen W, Gao F, Goward SN, Helder D, Helmer E, Nemani R, Oreopoulos L, Schott J, Thenkabail PS, Vermote EF, Vogelmann J, Wulder MA, Wynne R (2008) Free access to Landsat imagery. Science 320:1011. https://doi.org/10.1126/science.320.5879.1011a

32. Chen WY (2009) 3d visualization based on digital elevation model and remote sensing image. Sci Surv Mapp.

33. Fern á ndez J, Prieto JF, Escayo J, Camacho AG, Luz ó n F, Tiampo KF, Palano M, Abajo T, P é rez E, Velasco J, et al. (2018) Modeling the two-and three-dimensional displacement field in Lorca, Spain, subsidence and the global implications. Sci Rep 8:14782.

34. Huang Y, Yu M, Xu Q, Sawada K, Moriguchi S, Yashima A, Liu C, Xue L (2015) InSAR-derived digital elevation models for terrain change analysis of earthquake-triggered flow-like kandslides bases on ALOS/PALSAR imagery. Environ Earth Sci 73:7661-7668. https://doi.org/10.1007/s12665-014-3939-5

35. Yu M, Huang Y, Zhou J, Mao L (2017) Modeling of landslide topography based on micro-unmanned aerial vehicle photography and structure-from-motion. Environ Earth Sci 76:520. https://doi.org/10.1007/s12665-017-6860-x

36. Biggs J, Ebmeier SK, Aspinall WP, Lu Z, Pritchard ME, Sparks RSJ, Mather TA (2014) Global link between deformation and volcanic eruption quantified by satellite imagery. Nat Commun 5:3471. https://doi.org/10.1038/ncomms4471.

37. Biggs J, Pritchard ME (2017) Global volcano monitoring: what does it mean when volcanoes deform? Elements 13:17-22. https://doi.org/10.2113/gselements.13.1.17

38. Estoque RC, Murayama Y (2015) Classification and change detection of built-up lands from Landsat-7 ETM+ and Landsat-8 OLI/TIRS imageries: A comparative assessment of various spectral indices. Ecol Indic 56:205-217. https://doi.org/10.1016/j.ecolind.2015.03.037

39. Ma X, Tong X, Liu S, Ma Z (2017) Extraction of built-up areas in Chinese silk road economic belt based on DMSPOLS data. In: Proceedings of the 2017 IEEE International Geoscience and Remote Sensing Symposium, Fort Worth, TX, USA, pp 5877-5880 
40. Jiang W, He GJ, Long TF, Wang C, Ni Y, Ma RQ (2017) Assessing light pollution in China based on nighttime light imagery. Remote Sens 9:135. https://doi.org/10.3390/rs9020135

41. Kailin W (2019) Construction of DEM at the bottom of Baiyangdian Wetland Based on Remote Sensing Thematic Interpretation. Mod Geol 033:1098-1105

42. Jiachun L (2014) Remote sensing image interpretation and tectonic activity of major active faults in Yushu, Qinghai. Geol Bull 04:149-164

43. Xuhong W (2005) Research on Remote Sensing Image Data Mining Technology. Northwestern University

44. Okada Y (1985) Surface deformation due to shear and tensile faults in a halfspace. Bull Seismol Soc Amer 75:11351154

45.Camacho AG, Gonz á lez PJ, Fern á ndez J, Berrino G (2011) Simultaneous inversion of surface deformation and gravity changes by means of extended bodies with a free geometry: Application to deforming calderas. J Geophys Res 116:B10401.

46. Dzurisin D (2007) Volcano Deformation: Geodetic Monitoring Techniques; Springer-Praxis Books in Geophysical Sciences. Praxis Publishing Ltd., Chichester, UK, p 441

47. Herring T (2009) Treatise on Geophysics, Geodesy. 1st ed.; Volume 3. Elsevier, Amsterdam, The Netherlands, p 446

48.Fern á ndez J, Pepe A Poland MP, Sigmundsson F (2017) Volcano geodesy: Recent developments and future challenges. J Volcanol Geotherm Res 344:1-12.

49. Fern á ndez J, Prieto JF, Escayo J, Camacho AG, Luz ó n F, Tiampo KF, Palano M, Abajo T, P é rez E, Velasco J, et al. (2018) Modeling the two-and three-dimensional displacement field in Lorca, Spain, subsidence and the global implications. Sci Rep 8:14782.

50. Huang Y, Yu M, Xu Q, Sawada K, Moriguchi S, Yashima A, Liu C, Xue L (2015) InSAR-derived digital elevation models for terrain change analysis of earthquake-triggered flow-like landslides based on ALOS/PALSAR imagery. Environ Earth Sci 73:7661-7668. https://doi.org/10.1007/s12665-014-3939-5

51. Yu M, Huang Y, Zhou J, Mao L (2017) Modeling of landslide topography based on micro-unmanned aerial vehicle photography and structure-from-motion. Environ Earth Sci 76:520. https://doi.org/10.1007/s12665-017-6860-x

52. Pengcheng S (2013) Study on the impact of active fault on debris flow and its Quantitative Evaluation.

53. Sousa AMO, Gonçalves AC, da Silva JRM (2017) Above-ground biomass estimation with high spatial resolution satellite images. In: Tumuluru JS (ed.) Biomass Volume Estimation and Valorization for Energy. InTech: Rijeka, Croatia, Volume 2017, pp 47-70.

54. Sousa AMO, Gonçalves AC, Mesquita P, Marques da Silva JR (2015) Biomass estimation with high resolution satellite images: A case study of Quercus rotundifolia. ISPRS J Photogramm 101:69-79. https://doi.org/10.1016/j.isprsjprs.2014.12.004

55. Liu S, Tong X, Bruzzone L, Du P (2017) A novel semisupervised framework for multiple change detection in hyperspectral images. In: Proceedings of the 2017 IEEE International Geoscience and Remote Sensing Symposium, Fort Worth, TX, USA, pp 173-176

56. Amarsaikhan D, Ganzorig M, Blotevogel HH, Nergui B, Gantuya R (2009) Integrated approach to extract information from high and very high resolution RS images for urban planning. J Geogr Reg Plan 2:258-267

57. Li K, Chen Y (2018) A genetic algorithm-based urban cluster automatic threshold approach by combining VIIRS DNB, NDVI, and NDBI to monitor urbanization. Remote Sens 10:277. https://doi.org/10.3390/rs10020277

58. Xu H (2008) A new index for delineating built-up land features in satellite imagery. Int J Remote Sens 29:42694276. Https://doi.org/10.1080/01431160802039957

59. Xiang D, Tang T, Hu C, Fan Q, Su Y (2016) Built-up area extraction from polSAR imagery with model-based decomposition and polarimetric coherence. Remote Sens 8:685. https://doi.org/10.3390/rs8080685

60. Pesaresi M, Gerhardinger A, Kayitakire F (2008) A robust built-up area presence index by anisotropic rotationinvariant textural measure. IEEE J Sel Top Appl Earth Observations Remote Sens 1:180-192. https://doi.org/10.1109/JSTARS.2008.2002869

61. Waqar MM, Mirza JF, Mumtaz R, Hussain E (2012) Development of new indices for extraction of built-up area and bare soil from Landsat Data. Open Access Sci Rep 1:1-4 